Abstract
A climate crisis is inevitable unless developing countries limit carbon emissions
from the power sector in the near future. This will happen only if the costs of low-
carbon power production become competitive with fossil fuel power.
We focus on a leading candidate for investment: solar thermal or concentrating
solar power (CSP), a commercially available technology that uses direct sunlight
and mirrors to boil water and drive conventional steam turbines. Solar thermal
power production in North Africa and the Middle East could provide enough power
to Europe to meet the needs of 35 million people by 2020 .
We compute the subsidies needed to bring CSP to financial parity with fossil-fuel
alternatives. They conclude that large-scale deployment of CSP is attainable with
subsidy levels that are modest, given the planetary stakes. By the end of the
program, unsubsidized CSP projects are likely to be competitive with coal- and gas-
based power production in Europe.
The question is not whether CSP is feasible but whether programs using CSP
technology will be operational in time to prevent catastrophic climate change. For
such programs to spur the clean energy revolution, efforts to arrange financing
should begin right away, with site acquisition and construction to follow within a
year.

The Center for Global Development is an independent, nonprofit policy research organization that is dedicated to reducing global poverty and inequality and to making globalization work for the poor. This paper was made possible in part by financial support from the Australian Agency for International Development.

Use and dissemination of this Working Paper is encouraged; however, reproduced copies may not be used for commercial purposes. Further usage is permitted under the terms of the Creative Commons License. The views expressed in this paper are those of the author and should not be attributed to the board of directors or funders of the Center for Global Development. 


\title{
Desert Power: \\ The Economics of Solar Thermal Electricity For Europe, North Africa, and the Middle East
}

\author{
Kevin Ummel \\ David Wheeler
}

\section{Center for Global Development \\ December, 2008}

Thanks to Waleed Alsuraih, Husam Beides, Nancy Birdsall, Ken Chomitz, Michele de Nevers, Dennis de Tray, Chris Flavin, Chandra Govindarajalu, Kirk Hamilton, Dan Hammer, Robin Kraft, Lawrence MacDonald, Fred Morse, Paul Martin, Joel Meister, Alan Miller, John O'Donnell, and Mead Over and for valuable comments and suggestions. All remaining errors are our own. 


\section{Executive Summary}

A climate crisis is inevitable unless developing countries limit carbon emissions from the power sector in the near future. This will only happen if low-carbon technologies become costcompetitive for private investors, because feasible international subsidies for clean technology will be tiny relative to the needed sectoral investment. Success will require focusing on strategic investments that create a market cost advantage for clean power.

This paper focuses on a leading investment candidate, solar thermal or concentrating solar power (CSP), a commercially available technology that uses direct sunlight and mirrors to boil water and drive conventional steam turbines. We focus on the most promising near-term prospect for CSP expansion: export of electricity to Europe from the desert regions of the Middle East and North Africa (MENA), which receive some of the most intense solar radiation in the world. Recognizing this, the Union for the Mediterranean, initiated in July 2008 and composed of EU member states and non-EU Mediterranean nations, has adopted the goal of deploying 20 gigawatts of solar generating capacity in the region by 2020 .

The paper analyzes an expansion program that exports electricity to Europe from representative sites in Morocco, Libya, and Jordan. We compute the subsidies needed to bring CSP to financial parity with fossil-fuel alternatives in an assessment that considers project siting, power transmission, short- and long-run costs, power market characteristics and financing options. Construction begins in 2010, with 20 gigawatts of generating capacity and associated transmission infrastructure installed by 2020. Total delivery to Europe in 2020 is 55,000 gigawatt hours - enough to satisfy the power demand of 35 million people. The program directly averts about 2.7 billion tons of carbon dioxide ( $\mathrm{CO} 2)$ emissions over the lifetime of the facilities, and indirectly averts an additional 2.6 billion tons by accelerating cost reductions for investments outside the program.

We estimate that implementation will require international clean technology subsidies of about $\$ 20$ billion over ten years. By the end of the program, the expected profitability of unsubsidized CSP projects is competitive with that of coal and gas power generation in Europe. Over the full life of the program, the present value cost of $\mathrm{CO} 2$ averted is as low as $\$ 14$ per ton. This is a very modest carbon shadow price, even by conservative standards.

We conclude that large-scale deployment of CSP in the MENA region is attainable at levels of public subsidy that are modest, given the planetary stakes. The question is not whether CSP is feasible, but whether programs like the MENA initiative will be operational in time to prevent catastrophic climate change. For such programs to spur the clean energy revolution, efforts to arrange financing should begin right away, with site acquisition and construction to follow within a year. 


\section{Introduction}

Although carbon mitigation proposals have traditionally focused on developed countries, emissions from developing countries are growing so rapidly that they will probably account for one-half of atmospheric carbon loading by 2030 (Wheeler and Ummel, 2007). This will sharpen the dilemma for negotiators at the UN's Copenhagen conference in 2009, because a climate crisis is inevitable unless developing countries begin limiting their carbon emission in the near future. This will only happen if carbon-intensive technologies become more costly than clean technologies, via regulation of the former or significant cost reduction for the latter. The first option seems unrealistic: Poor countries are unlikely to accept carbon regulation at Copenhagen for several reasons. They favor low-cost power (which is often carbon-intensive) because they remain focused on poverty reduction. In addition, they remain unwilling to shoulder an additional cost burden because they rightly view their historical role in creating the climate crisis as modest. Finally, we can scarcely expect poor countries to regulate global emissions when they cannot even control local pollutants that kill, injure and damage the livelihoods of millions of their citizens every year.

The second option, in contrast, does seem feasible. Developing countries may well agree to limit carbon emissions if developed countries make a credible offer to cover the incremental cost of clean technologies. Anticipating this condition, the US, UK and Japan have recently proposed a Clean Technology Fund (CTF) and delegated its management to the World Bank, citing the Bank's global experience with large energy projects (McCormick, 2008). In principle this offers a way forward, but potentially-critical problems of scale and cost must be considered. To assess their significance, this paper considers the prospects for clean technology promotion in the power sector. Power and heat generation are responsible for over $27 \%$ of total CO2 
emissions, and the proportion is rising (IPCC, 2007). Even if clean technology subsidies are large by historical standards, they will inevitably be tiny relative to the needed investment in this sector. Meeting future energy demand will require \$26 trillion in infrastructure investment between now and 2030, more than half of it in the developing world (IEA, 2008). Private investors will dominate the sector, and they will only choose renewable technology if it costs less than fossil-fired power. To succeed, donor institutions will have to focus their relatively modest resources on strategic investments that create a market cost advantage for clean power. If this cannot be achieved, clean technology subsidies are unlikely to be provide more than a palliative. Fortunately, our review of the evidence suggests that such an achievement is possible for a handful of clean technologies that can be developed at the requisite scale in the near future. Given the rapidly-closing window for action that can prevent a climate catastrophe, identifying and exploiting those limited options is a critical task for the global community.

The leading candidate may be solar thermal or concentrating solar power (CSP), which uses direct sunlight and mirrors to boil water and drive conventional steam turbines. The necessary technology and engineering are straightforward, no exotic materials are required, and commercial facilities have been in operation for more than 20 years. About 500 MW of CSP generating capacity is currently installed worldwide, with plans to add an additional 6,000 MW by 2012 - most of it in California and Spain. ${ }^{1}$ A central task for the global community is to open a similar expansion path for low- and middle-income countries. In this paper, we consider the most promising near-term prospect: the desert regions of the Middle East and North Africa (MENA), which receive some of the most intense solar radiation in the world. Much of it falls on largely-uninhabited land with little or no agricultural potential and, consequently, a low

\footnotetext{
${ }^{1}$ http://www.earth-policy.org/Updates/2008/Update73 data.htm\#table1
} 
opportunity cost of utilization. Given these favorable conditions, the technical potential for exploitation of MENA solar resources is nearly limitless.

Potential demand for these resources in nearby Europe is also huge. With the European Union planning to reduce member countries' greenhouse emissions by at least $15 \%$ from current levels by 2020, mostly through cap-and-trade regulation in the power sector, the regional demand for carbon-free electricity is intense and growing. At the same time, geopolitical considerations argue for reduced dependence on Russian natural gas and stronger political and economic integration with the southern Mediterranean region. In addition, MENA governments are interested in exploiting solar resources to meet rapidly-growing domestic demand, while redirecting natural gas production toward more profitable export opportunities. Recognizing these potential benefits, the Union for the Mediterranean, initiated in July 2008 and composed of EU member states and non-EU Mediterranean nations, has adopted the goal of deploying 20 gigawatts of solar generating capacity in the region by 2020 .

Extensive studies of MENA solar potential and technical feasibility have been conducted in the past, particularly the excellent MED-CSP and TRANS-CSP projects led by the German Aerospace Center (DLR 2005, 2006). We build on that work, providing estimates that reflect more recent information about input prices and CSP learning curves. We focus particularly on the subsidies needed to promote large-scale private-sector expansion of CSP in MENA during the coming decade, and the effect of alternative financing options on project profitability.

The remainder of the paper is organized as follows. In Section 2, we present a GIS analysis that identifies prospective solar fields in MENA and the potential for both domestic supply and export of electricity to Europe. Section 3 develops cost estimates for CSP technology and associated transmission systems, as well as coal- and gas-fired alternatives. In Section 4, we 
employ a simple financial model to compare the expected profitability of competing power generation options. Section 5 estimates the scale of international subsidies needed to make CSP projects as appealing to investors as fossil-fueled alternatives in Europe and selected MENA countries. Section 6 estimates the total cost of an expansion program capable of making CSP generation as profitable as European fossil fuel alternatives within 10 years. In Section 7, we provide a summary and conclusions. 


\section{Spatial Analysis of Potential Solar Fields}

Figure 1 shows the distribution of average annual direct normal irradiance (DNI) across Europe and the MENA region. Areas with DNI above $5 \mathrm{kWh} / \mathrm{m}^{2} /$ day are preferred for CSP operation and are denoted by the hatch pattern. While Europe exhibits good solar resources in southern Spain and Turkey during some parts of the year, far greater potential lies in the MENA countries to the south.

\section{Figure 1: Average Annual DNI in Europe and MENA Region ${ }^{2}$}

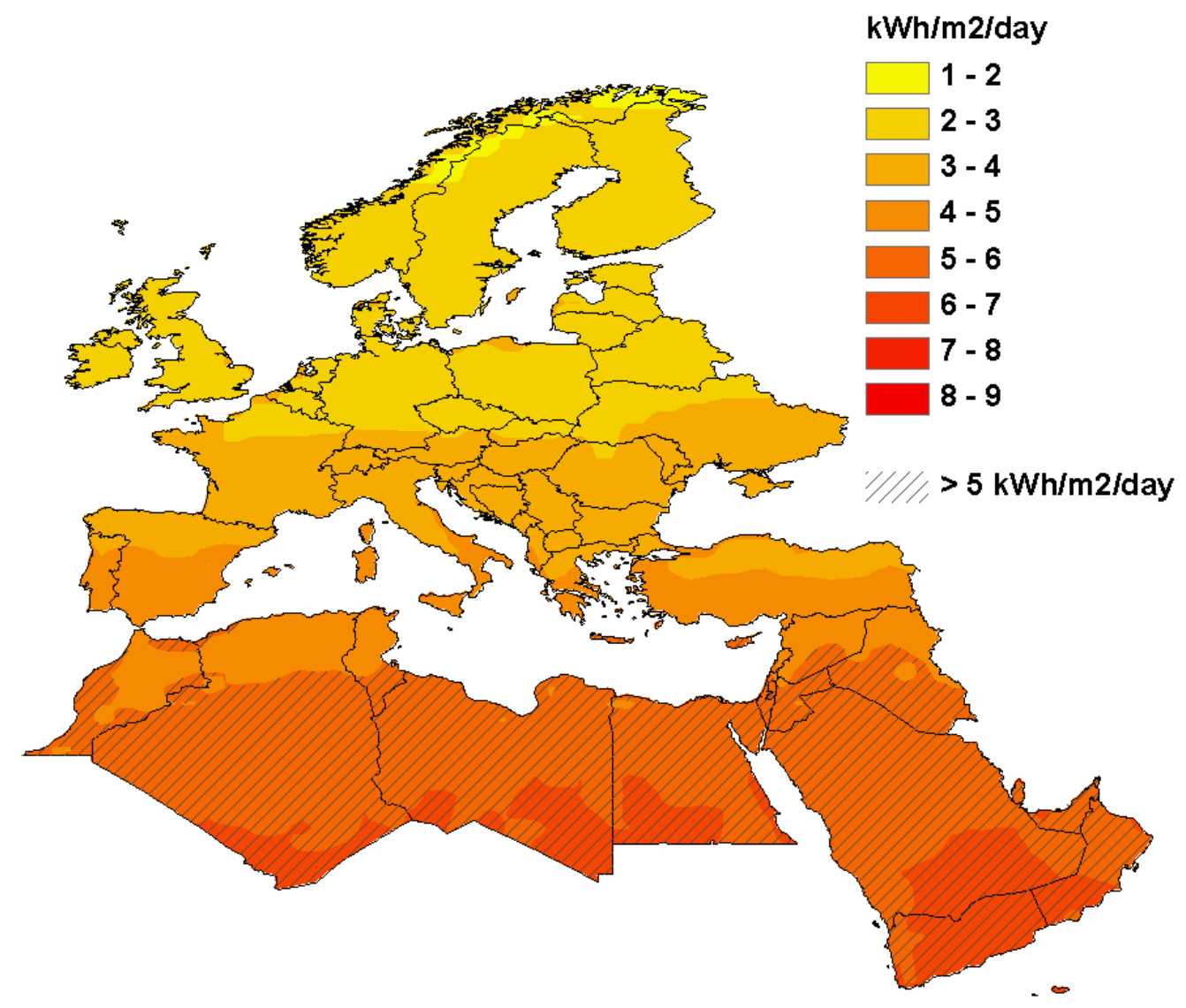

We identify areas in the MENA region suitable for large-scale, year-round operation of CSP facilities by applying a series of spatial filters that select for important site criteria. The layers include information on solar radiation levels, land cover and use, land forms, population

\footnotetext{
${ }^{2}$ Data interpolated from a global dataset produced by NASA's Surface meteorology and Solar Energy (SSE) program (http://eosweb.larc.nasa.gov/sse/).
} 
density, and location of water sources and protected areas. We combine the results with information on the location of roads, as well as existing and potential transmission corridors, to determine areas of likely lowest-cost deployment. Our methodology identifies five preferred sites, based on their potential for domestic power supply and/or export of electricity to Europe.

High-resolution data on direct normal irradiance come from the Solar and Wind Energy Resource Assessment (SWERA) of the United Nations Environment Programme. ${ }^{3}$ The dataset contains monthly and annual average DNI at about 40-km ( 22 arc-minute) resolution for Africa, most of the Arabian Peninsula, and the Near East. ${ }^{4}$ We assume that CSP technologies require DNI of at least $5 \mathrm{kWh} / \mathrm{m}^{2} /$ day and retain areas where the minimum monthly average meets or exceeds this amount. This identifies areas with high probability of year-round operation. Figure 2 shows areas within the study region that meet the solar radiation threshold.

\section{Figure 2: Minimum monthly DNI greater than $5 \mathrm{kWh} / \mathrm{m}^{2} / \mathrm{day}$}

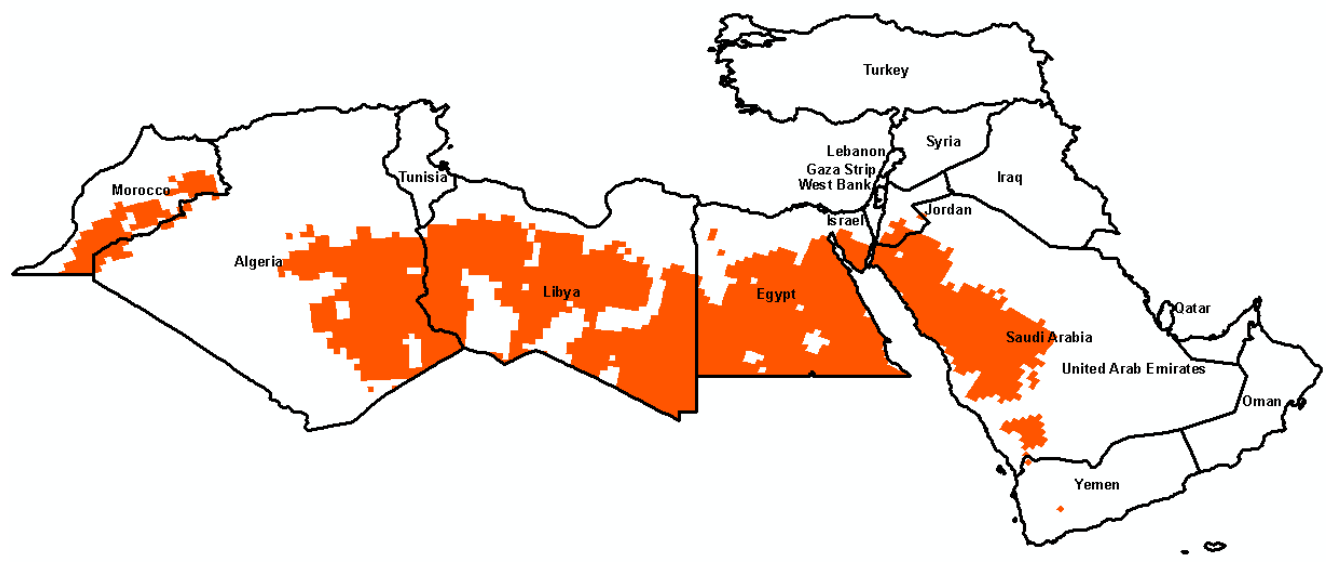

To identify areas with suitable land cover characteristics, we use Global Land Cover 2000 (GLC2000) datasets at 1-km resolution from the Joint Research Council. ${ }^{5}$ Selected areas have

\footnotetext{
${ }^{3}$ http://swera.unep.net/

4 The DNI dataset does not extend to the northern third of Turkey, UAE, Qatar, or northeast Oman.

${ }^{5}$ http://www-tem.jrc.it/glc2000/
} 
land cover classified as shrubland, grassland, gravel and stone, bare rock, stony desert, and hardpan; this specifically excludes any cropland from consideration.

We also identify a range of unsuitable features. We use the Harmonized World Soil Database to screen for shifting sand dunes and corrosive salt flats incompatible with heavy construction. Oak Ridge National Laboratory's 30 arc-second LandScan population database enables us to identify inappropriate settled areas with population densities exceeding 100 persons per square km. ${ }^{6}$ Data on inland bodies of water come from the 1992 Digital Chart of the World compiled by the United States Defense Mapping Agency. ${ }^{7}$ Areas protected from development by national law or international treaties are identified by the UNEP World Database on Protected Areas. ${ }^{8}$ We apply a $4-\mathrm{km}$ safety buffer to sand dunes and a $2-\mathrm{km}$ buffer to all other unsuitable features.

We identify sufficiently flat terrain using a slope database developed by the U.S. Geological Survey for global landslide analysis and derived from high-resolution surface elevation data retrieved by NASA's Shuttle Radar Topography Mission (Verdin et al., 2007). To ease computational requirements, we use mean slope values generated at 30 -arc second resolution instead of the original 3-arc second grid. We exclude from consideration areas that exhibit an average slope greater than $2 \%$.

Areas that are close to transportation infrastructure will have lower construction and maintenance costs than more remote locales. We create a composite database of the MENA regional road network by combining data from the International Steering Committee for Global Mapping, the Digital Chart of the World, and a layer constructed from Michelin road maps by

\footnotetext{
${ }_{7}^{6} \mathrm{http}: / /$ www.ornl.gov/sci/landscan/index.html

7 http://biogeo.berkeley.edu/bgm/gdata.php

8 http://sea.unep-wcmc.org/wdbpa/
} 
Andy Nelson of the World Bank in 2004. ${ }^{9}$ Figure 3 displays areas meeting our screening criteria for potential low-cost, year-round deployment of CSP technology; Figures 4 and 5 show Western and Eastern MENA insets, respectively, with a road network overlay. We exclude areas north of Jordan in Figure 5, since they do not meet the solar radiation threshold.

Figure 3: Areas meeting radiation and low-cost siting criteria

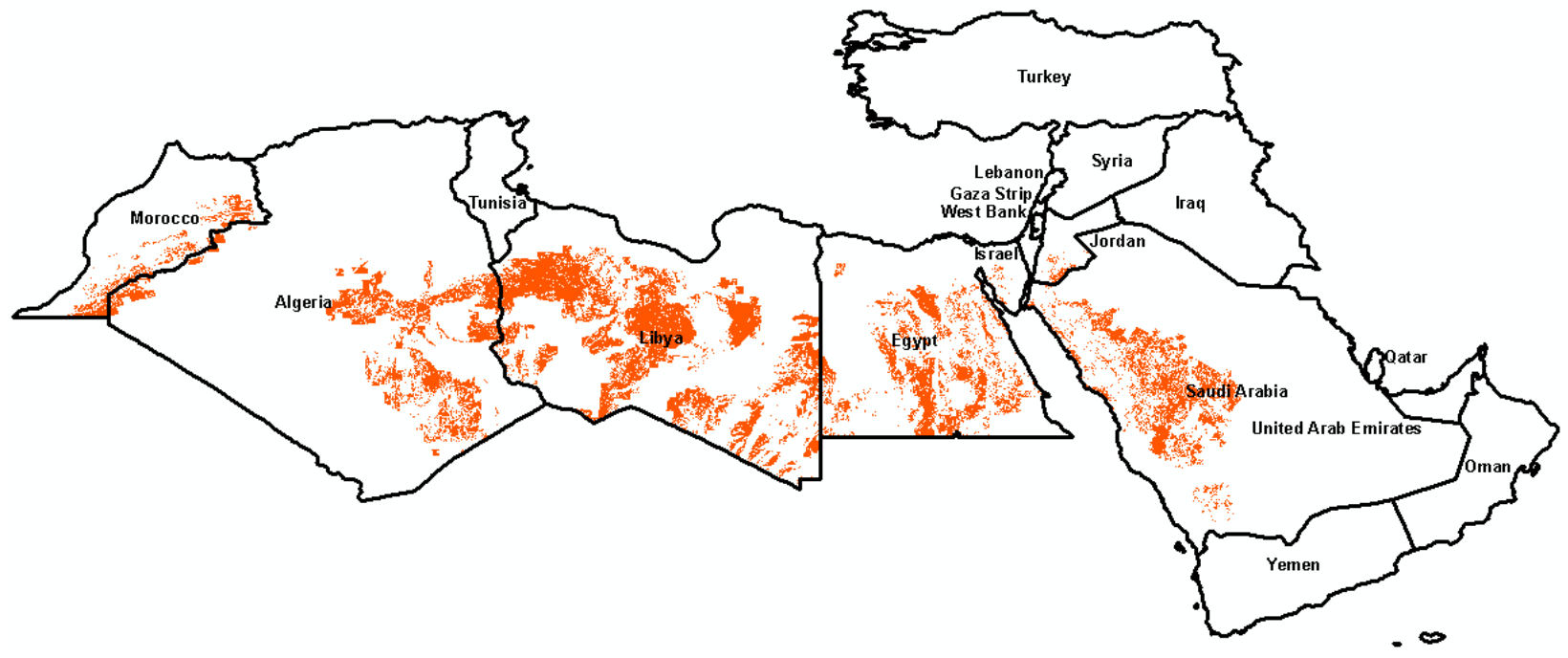

Figure 4: Western MENA inset with road network overlay

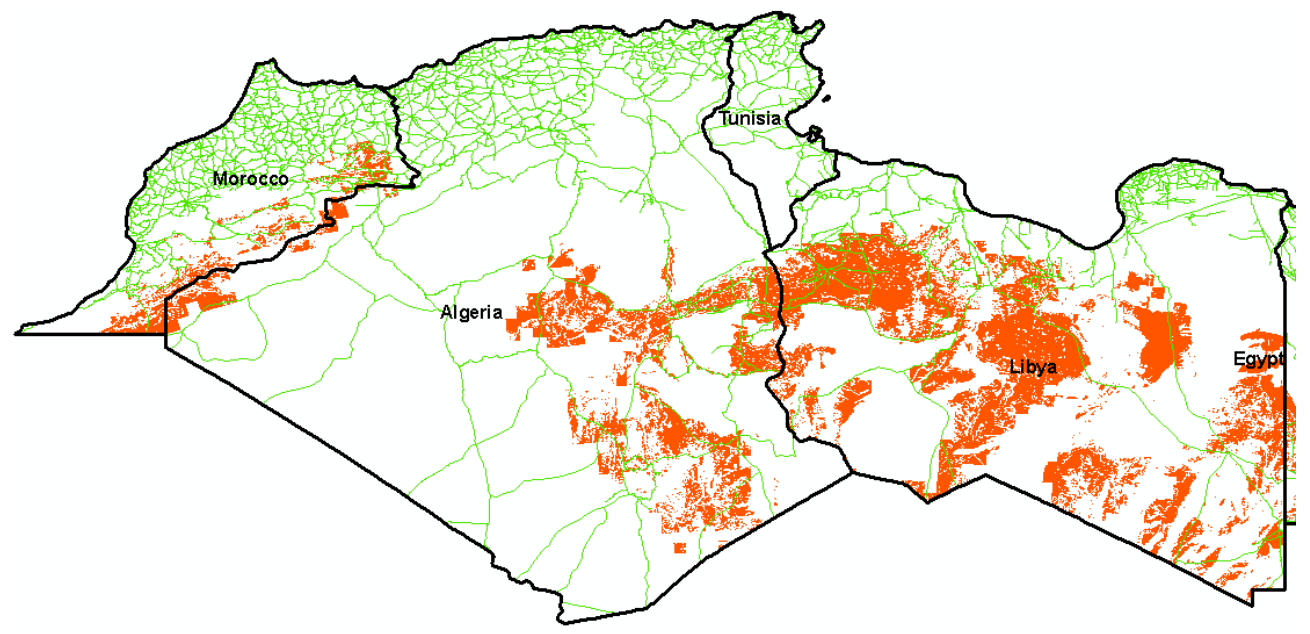

\footnotetext{
${ }^{9}$ http://www.iscgm.org/cgi-bin/fswiki/wiki.cgi
} 


\section{Figure 5: Eastern MENA inset with road network overlay}

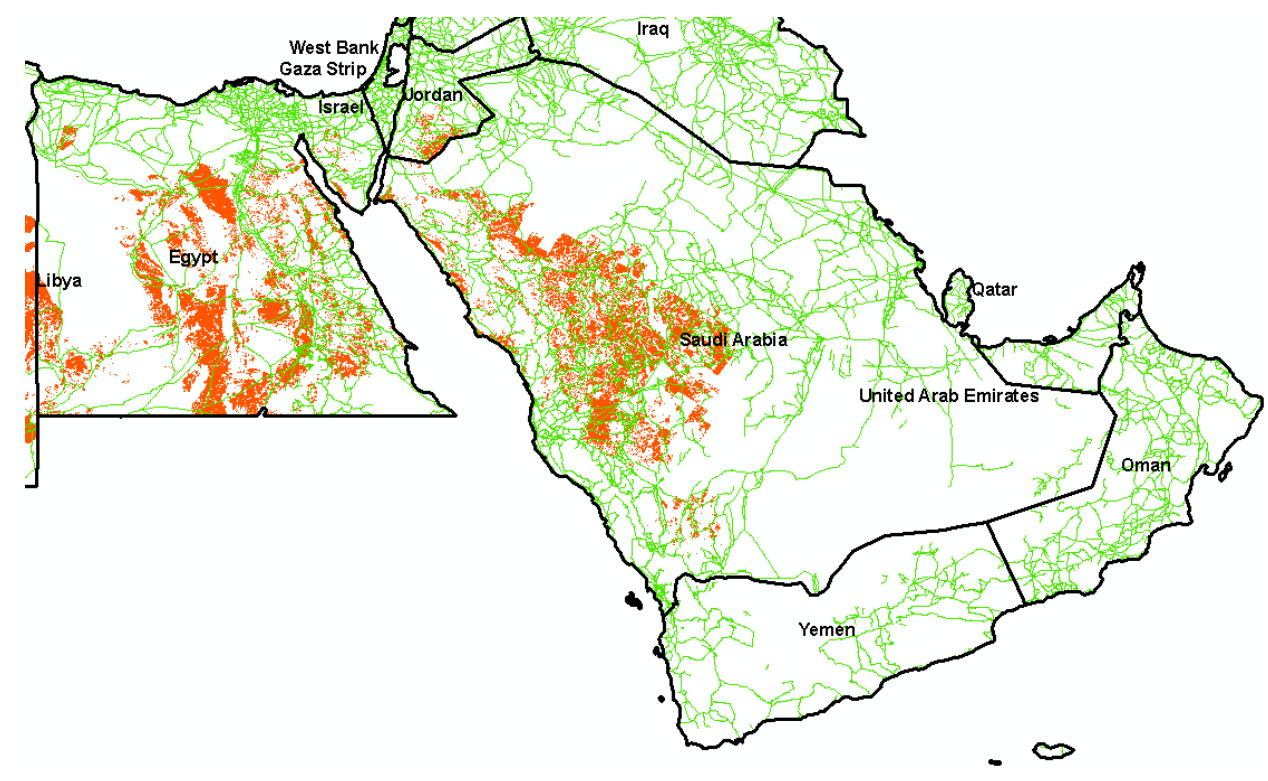

The transmission component of the spatial analysis identifies locales with the potential for interconnections with the domestic grid and/or export of electricity to southern Europe. We are not aware of publicly-available, digitized maps of existing power transmission lines in the MENA region, so we employ country-level maps from the Global Energy Network Institute. They provide the approximate location of primary lines and are matched against the areas highlighted in Figure 3.

We assess potential Mediterranean submarine cable crossings by analyzing 1 arc-minute bathymetric data from the British Oceanographic Data Centre. ${ }^{10}$ The maximum depth of highvoltage direct current (HVDC) submarine cables considered in recent years is about 2,000 meters below sea level (Cova et al., 2005). Masking areas deeper than this threshold identifies two primary undersea crossings. The first is the very short crossing between Morocco and Spain via

\footnotetext{
${ }^{10}$ http://www.bodc.ac.uk/data/online_delivery/gebco/
} 
the Strait of Gibraltar. The second departs from Tunisia, using Sardinia and Corsica as stepping stones to the Italian mainland. We also consider an overland connection through the Near East.

In consultation with World Bank staff working on energy infrastructure in the MENA region, we have identified CSP sites with particular potential for domestic interconnection (i.e., proximity to backbone lines, opportunities for system redundancy, etc.) and/or transmission to Europe. Taking into consideration the density of transportation infrastructure and radiation and terrain constraints, we arrive at five preferred solar fields for CSP development. All of these fields are thought to have good interconnection potential with existing domestic or regional grids. Two of the fields (in Morocco and Libya) have potential access to Mediterranean submarine crossing points. A third (in Jordan) has potential access to Turkey via an overhead HVDC line through Jordan and Syria.

Figure 6 shows the locations and approximate sizes of these fields, as well as the envisioned transmission infrastructure required to move electricity to demand centers. Their total land area is about 110,000 square kilometers - roughly the size of Bulgaria. The contiguous Libyan field and disparate Saudi fields north of Mecca constitute $80 \%$ of the total. The Jordanian field is the smallest at about $1,700 \mathrm{~km}^{2}$, but even that area is capable of generating between 132 and 195 TWh per year, depending on plant configuration. The whole $110,000 \mathrm{~km}^{2}$ of preferred area for CSP exploitation is sufficient to meet 50-70\% of worldwide electricity production, or about three times the current power consumption of Europe. 
Figure 6: Location of Preferred Solar Fields and Transmission Corridors ${ }^{11}$

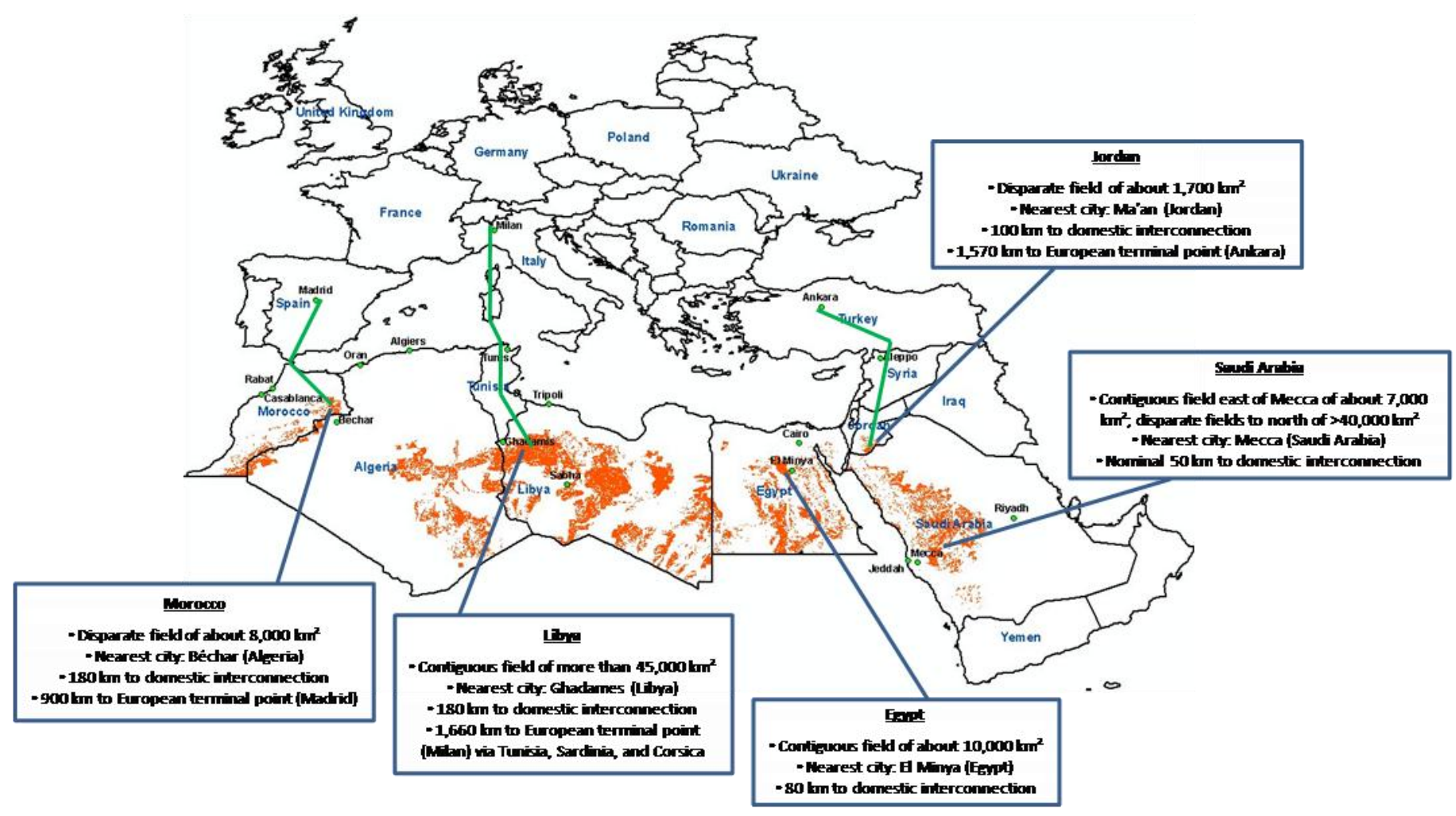

${ }^{11}$ European transmission lines (green) are for illustration only. See May (2005) for description of preferred routing. 


\section{Power Generation and Transmission Infrastructure Costs}

Assessing the comparative costs of power generation projects is difficult. Quoted prices for materials and equipment (steel, cement, turbines, electric generators, etc.) can vary considerably across countries and projects. The same is true for the cost of construction labor and operational and maintenance personnel. Coal, oil, and gas differ in quality and cost, and their future prices are difficult to predict. Full project costs, especially for renewable technologies, are also influenced by the physical characteristics of project sites. In addition, expected profitability, which determines whether or not a project is actually pursued, is affected by electricity tariff structures, tax incentives, renewable portfolio standards, debt-to-equity ratios, finance and insurance arrangements, capital cost schedules, investors' expected returns, and, importantly, expectations about regulation of greenhouse gas emissions.

We apply a simplified methodology that allows us to compare CSP to coal and gas power plants, the primary alternatives in the MENA region and Europe. In this section, we develop cost estimates for the relevant generation technologies and transmission systems. Later, we embed these costs in a simple financial model to assess expected project profitability and financing requirements.

\subsection{Power Generation Costs}

Direct generating cost data are generally not available for individual countries, so we must estimate them using a range of other sources. We take recent capital cost data for coal and gas plants from ESMAP (2008), which provides estimates for the United States and India as of January 2008. ${ }^{12}$ We draw or estimate performance and technical specifications and operations

\footnotetext{
${ }^{12}$ http://www.esmap.org/filez/pubs/724200833229_power_prices.pdf
} 
and maintenance costs from extensive studies by NETL (2007), ${ }^{13}$ MIT (2007), ${ }^{14}$ and ESMAP (2007). ${ }^{15}$ Estimated capital and operating costs for CSP plants come from our assessment of four solar thermal plant proposals currently under review by the California Energy Commission, ranging from $177 \mathrm{MW}$ to $750 \mathrm{MW} .^{16}$ The technologies employed include parabolic trough, power tower, Stirling-dish, and compact linear Fresnel reflector (CLFR).

Since the preferable CSP technology may differ by locale and application, we use the average expected performance and costs of the projects reviewed. The average reported capital cost is $\$ 2.77$ per watt. Since it is unclear whether the reported figures include project contingencies, we increase this figure by $20 \%$ to arrive at an estimate of $\$ 3.32$ per watt for U.S. plants without thermal storage. We also assign a $20 \%$ markup to operating costs for process contingencies.

Little information is available on the technical and economic parameters of solar thermal storage, whereby excess heat generated during the day is used to run a plant's power block at night. ${ }^{17}$ We develop an estimate using two sources: the cost of saline storage for parabolic trough CSP, as reported in NREL's Solar Advisor Model; ${ }^{18}$ and modeling results for the storage potential of compact linear Fresnel reflector CSP, which allow us to estimate the additional array requirements for providing 24-hour power production (Mills and Morgan, 2008). ${ }^{19}$

\footnotetext{
${ }_{14}^{13} \mathrm{http} / / / \mathrm{www}$.netl.doe.gov/energy-analyses/baseline_studies.html

14 http://web.mit.edu/coal/

15 http://www.esmap.org/filez/pubs/4172008104859_Mini_Grid_Electrification.pdf

${ }_{16}^{16} \mathrm{http://www.energy.ca.gov/siting/solar/index.html}$

${ }^{17}$ Conversations with CSP executives have elicited different opinions on the profitability of thermal storage for nighttime power generation. Since the highest electricity tariffs will be offered during peak-use daylight hours when most consumption occurs, the cost of storage must be low enough to remain profitable during off-peak hours. Since MENA-to-Europe transmission is South-to-North, and there is strong temporal alignment of peak electricity consumption and production, storage is unlikely to be a limiting factor for CSP in the short term.

${ }^{18} \mathrm{https}: / /$ www.nrel.gov/analysis/sam/

${ }^{19}$ Estimated requirements are based on solar multiples (SM): the ratios of energy produced to energy converted to power during daylight hours. The higher the ratio, the greater the energy that can be stored for nighttime power production. Mills and Morgan (2008) report a financially optimal solar multiple (SM) of 3 for 16-hour storage configurations. Ausra Inc.'s planned Carrizo (California) CLFR plant without storage exhibits a solar multiple of
} 
We adjust these figures to generate cost estimates for selected MENA and European countries. We adjust coal and gas capital costs for the U.S. and India using comparative price indices for gross fixed capital formation, which includes machinery and construction, for MENA, European countries, the U.S., and India (ICP, 2008). In the case of CSP, we use reported differences in labor construction wages, worker productivity, and steel, concrete, and turbine prices between the United States and India as a starting point (ESMAP, 2008). Overall, we estimate that CSP capital costs could be lower by $12 \%$ or more when construction occurs in India instead of the United States. We then apply price index ratios to estimate how much of this reduction should apply in the case of specific MENA countries.

We construct fuel cost trajectories for European coal and gas using growth projections from the Energy Information Administration for the U.S. market through 2030, and a linear extrapolation of International Energy Agency projections to 2050. Applying the resulting growth rates to estimates of current delivered European prices for power generation, we arrive at the scenarios presented in Figure 7.

Figure 7: Assumed Trajectory for Delivered Cost of European Coal and Gas (2010-2050)

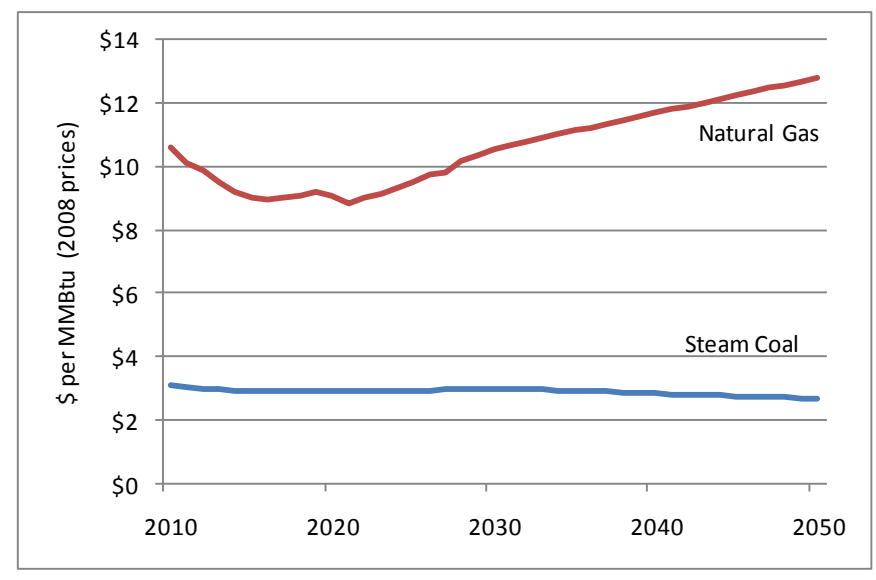

1.93. For the CSP storage cost estimate, we assume that array costs are $60 \%$ of total capital outlays and must be scaled from a SM of 1.93 to a SM of 3 for 24-hour power production. 
For MENA countries, we must account for the effect of significant natural gas subsidies. Razavi (2008) reports the post-subsidy price of natural gas in 2006 for a sample of MENA countries. Since then, global natural gas prices have risen nearly $50 \%$. We assume that the subsidized price of gas has increased by a similar percentage in countries where 2006 data are available. After consultation with World Bank MENA staff, we assign Morocco a post-subsidy price of $\$ 7$ per MMBtu and Jordan a price of $\$ 6$ per MMBtu (Table 1). Future MENA gas prices are assumed to have the same growth rate as the European price.

\begin{tabular}{|cc|}
\hline $\begin{array}{c}\text { Table 1: Subsidized Price of Gas in Selected } \\
\text { MENA Countries }\end{array}$ \\
\hline Assumed US\$ per MMBtu in 2008 \\
\hline Morocco & $\$ 7.00$ \\
Libya & $\$ 1.33$ \\
Egypt & $\$ 1.76$ \\
Saudi Arabia & $\$ 1.11$ \\
Jordan & $\$ 6.00$ \\
\hline $\begin{array}{l}\text { Sources: World Bank staff estimates (Morocco and Jordan). } \\
\text { Razavi (2008) with adjustment for increase in global natural } \\
\text { gas price index from 2006 to 2008 (Libya, Egypt, and Saudi } \\
\text { Arabia). }\end{array}$ \\
\hline
\end{tabular}

We combine these factors to calculate the levelized cost of electricity (LCOE) for each plant type and locale. The LCOE is the present value of expected costs over the lifetime of a power plant, divided by the discounted stream of power production over the same period. Costs include initial construction (capital costs), the annual costs of operating and maintaining the facility, and, in the case of fossil fuel projects, the annual cost of fuel. Power production is determined by the size of the plant and the assumed capacity factor.

The LCOE allows for comparison of technologies with similar operating specifications and financial arrangements, as is generally the case for coal and gas power plants but not necessarily for CSP. In the following section, we employ a simple financial model to appropriately compare 
CSP with the fossil fuel alternatives. Table 2 reports the estimated levelized cost of electricity for various configurations. Within the MENA region, coal is considered a viable generating option only in Morocco, and it is assigned the same coal price and trajectory as Europe. Table 2 also reports the effect on the LCOE of including a carbon charge (tax) of either $\$ 15$ or $\$ 30$ per metric tons of $\mathrm{CO} 2$ emitted. A complete explanation of data sources and techniques is provided in Wheeler, Ummel, and Hammer (forthcoming). 


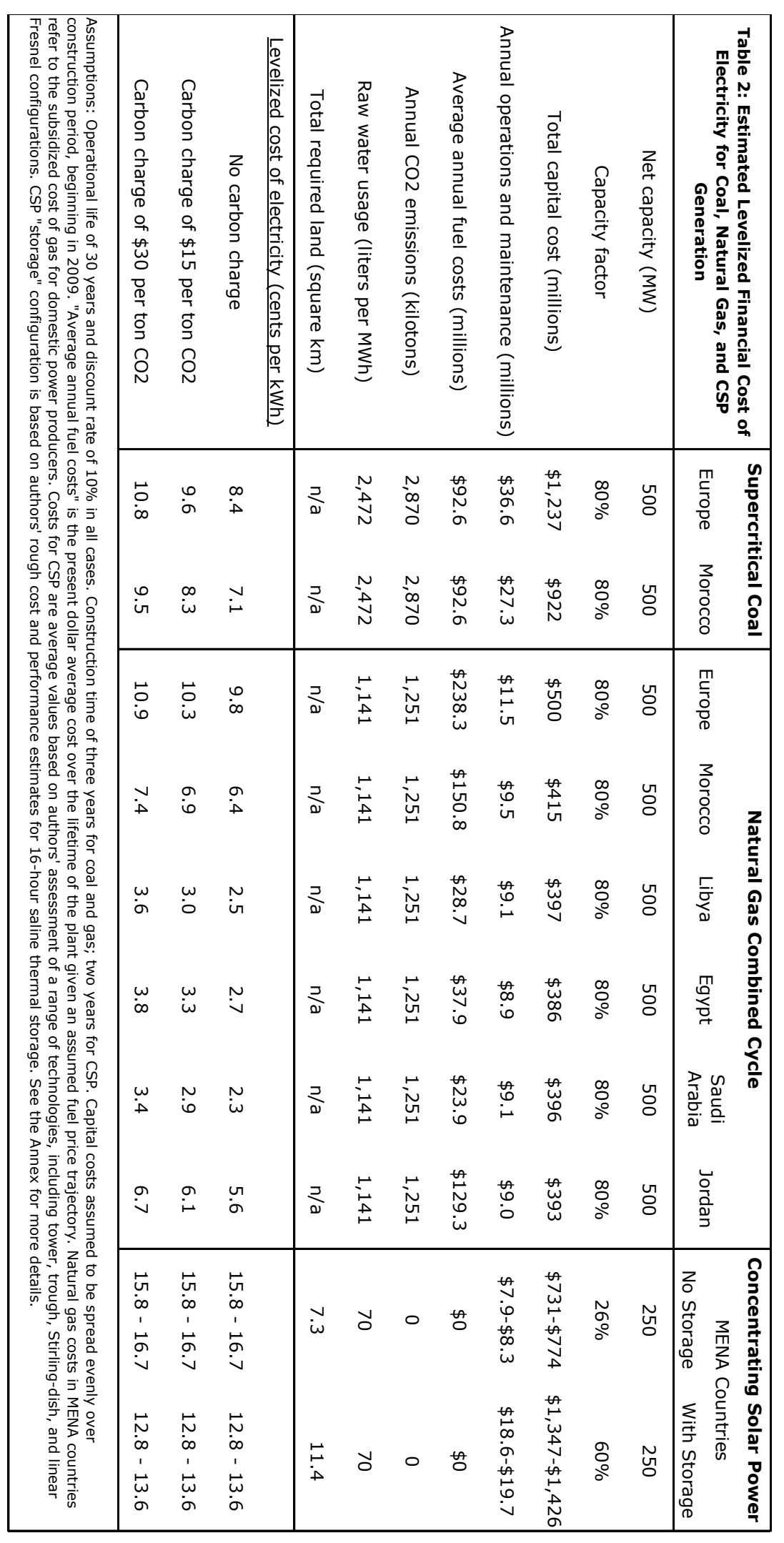




\subsection{Power Transmission Costs}

We estimate costs for two transmission alternatives. The first is domestic (local) transmission of electricity from the CSP project site to the closest preferred interconnection with the existing in-country grid, using high-voltage alternating current (HVAC) lines. Based on recent construction of such systems in the region and conversations with World Bank staff, we estimate a cost of $\$ 200,000$ per $\mathrm{km}$ and about $\$ 20$ million total for two substations on either side of the line. Losses are assumed to be $12 \%$ per $1,000 \mathrm{~km}$ and $0.2 \%$ per station (DLR, 2006).

For export of power to Europe, we estimate the cost of high-voltage direct current (HVDC) transmission from the CSP project site to one of three locations on the European mainland. Using the sea-floor depth analysis described in Section 2 and previous GIS modeling of environmentally- and technically-preferable transmission corridors from North Africa to Europe, we calculate the costs for three representative routes (May, 2005). The Moroccan solar site connects via an overland line to the Strait of Gibraltar, where it makes a submarine cable crossing, and continues overland to Madrid. The Libyan site connects via an overland line through Libya and Tunisia, then undersea and overland through Sardinia and Corsica to the Italian mainland, terminating in Milan. The Jordanian site connects via an exclusively overhead line traveling through Jordan and Syria and terminating in Ankara, Turkey.

The HVDC transmission routes require the construction of AC-DC converter stations on both ends of HVDC lines/cables. The assumed cost is $\$ 250$ million per station, based on reported expected costs by the Saudi Electricity Company (SEC) for ongoing transmission projects. Overhead bi-pole HVDC lines are assumed to cost $\$ 280,000$ per $\mathrm{km}$ by the SEC; the cost of submarine cable is assumed to be five times the cost of overhead line. Power losses are set to $6 \%$ per $1,000 \mathrm{~km}$ for overhead line, $3.3 \%$ per $1,000 \mathrm{~km}$ for submarine cable, and $0.7 \%$ per 
converter station (May, 2005; DLR, 2006). In the case of both AC and DC transmission, annual operation and maintenance costs are specified as $2 \%$ of the total project capital cost (ESMAP, 2007).

For AC configurations, we assume a bi-pole line with a power rating of $500 \mathrm{MW}$ and voltage of $+/-400 \mathrm{kV}$. The HVDC specification includes a power rating of 3,000 MW and a voltage of $+/-500 \mathrm{kV}$. We assume that initial domestic transmission will be at smaller scale, while the decision to construct a line for dedicated export will necessitate a considerably larger power rating. ${ }^{20}$ Table 3 provides estimated capital and O\&M costs and power losses for domestic and European transmission scenarios for each of the five preferred solar sites. While the overall cost of the HVDC systems is far higher, they have significantly greater power throughput.

\begin{tabular}{|c|c|c|c|c|c|c|c|c|}
\hline \multirow{2}{*}{$\begin{array}{l}\text { Table 3: Estimated Cost of } \\
\text { Domestic and European } \\
\text { Transmission Scenarios }\end{array}$} & \multicolumn{4}{|c|}{ Domestic Supply (HVAC; 500 MW) } & \multicolumn{4}{|c|}{ Export to Europe (HVDC; 3,000 MW) } \\
\hline & $\begin{array}{l}\text { Total } \\
\text { distance } \\
(\mathrm{km})\end{array}$ & $\begin{array}{l}\text { Capital } \\
\text { costs } \\
\text { (millions) }\end{array}$ & $\begin{array}{l}\text { Annual } \\
\text { O\&M } \\
\text { (millions) }\end{array}$ & $\begin{array}{c}\text { Trans. } \\
\text { Power Loss }\end{array}$ & $\begin{array}{l}\text { Total } \\
\text { distance } \\
(\mathrm{km})\end{array}$ & $\begin{array}{l}\text { Capital } \\
\text { costs } \\
\text { (millions) }\end{array}$ & $\begin{array}{l}\text { Annual } \\
\text { O\&M } \\
\text { (millions) }\end{array}$ & $\begin{array}{c}\text { Trans. } \\
\text { Power Loss }\end{array}$ \\
\hline Morocco & 180 & $\$ 56$ & $\$ 1.1$ & $2.6 \%$ & 900 & $\$ 777$ & $\$ 15.5$ & $6.9 \%$ \\
\hline Libya & 180 & $\$ 56$ & $\$ 1.1$ & $2.6 \%$ & 1660 & $\$ 1,487$ & $\$ 29.7$ & $12.6 \%$ \\
\hline Egypt & 80 & $\$ 36$ & $\$ 0.7$ & $1.4 \%$ & $\mathrm{n} / \mathrm{a}$ & $n / a$ & $\mathrm{n} / \mathrm{a}$ & $\mathrm{n} / \mathrm{a}$ \\
\hline Saudi Arabia & 50 & $\$ 30$ & $\$ 0.6$ & $1.0 \%$ & $\mathrm{n} / \mathrm{a}$ & $\mathrm{n} / \mathrm{a}$ & $\mathrm{n} / \mathrm{a}$ & $\mathrm{n} / \mathrm{a}$ \\
\hline Jordan & 100 & $\$ 40$ & $\$ 0.8$ & $1.6 \%$ & 1570 & $\$ 940$ & $\$ 18.8$ & $10.8 \%$ \\
\hline
\end{tabular}

\footnotetext{
${ }^{20}$ Full commitment to exporting large quantities of solar power to Europe would require HVDC transmission systems on the scale of the Itaipu project in Brazil, where a maximum of 6,000 MW can be transmitted in a single line. In its assessment of North Africa-Europe transmission, DLR (2005) assumes future construction of 5,000 MW HVDC lines.
} 


\section{Assessing the Profitability of CSP and Fossil Fuel Alternatives}

A key difference between CSP and fossil-fueled power plants is the temporal distribution of costs. While CSP facilities face higher upfront capital costs, their fuel source (sunlight) is free. Thermal power plants, on the other hand, typically have lower initial costs but incur annual fuel costs for the life of the plant. As a result, CSP and fossil fuel projects necessarily pursue different financing arrangements.

Another important distinction is the nature and timing of power production. CSP facilities without thermal storage only produce power during daylight hours, while fossil-fueled plants can operate continuously. Since electricity prices are often higher during the day than at night, CSP and fossil-fueled plants will typically receive different revenues per unit of electricity delivered to the grid.

Given these factors, the LCOE will not necessarily provide a suitable means of comparing CSP project feasibility with fossil fuel alternatives. Appropriate evaluation should be based on expected profitability. As we mentioned earlier, numerous factors can influence the financial prospects of a project. Our approach to assessing profitability uses a simple financial model that takes into account the capital and operating costs for both generation and transmission infrastructure (detailed in Section 3), as well as key financial variables: the price of electricity, debt-to-equity ratio, interest rate on debt, corporate income tax rate, and potential subsidies. We also make adjustments for expected transmission and distribution losses.

Two financial measures are of particular interest. With respect to debt, lenders will only provide credit if the expected cash flow is sufficient to cover annual debt service payments (interest and principle) plus a risk premium. The ratio of expected post-tax revenue to annual debt service (the "annual debt service coverage ratio" (ADSCR)) is typically used to determine 
whether a loan is sound. Lenders have historically required an ADSCR between 1.2 and 1.5, depending on project risk and other factors (Kistner and Price, 1999).

For equity stakeholders, the expected internal rate of return (IRR) is the primary means of determining whether a project is worthy of investment. The IRR is the interest rate required to set the net present value of an investor's cash flow (revenues minus expenditures) to zero. The expected IRR provides a means of comparing the overall profitability of competing power generation projects (or other investment opportunities) where the LCOE is insufficient.

Generating these metrics requires an estimated revenue stream for each plant configuration. The retail price of electricity will differ depending on the sale location and (potentially) time of day. Using information on representative consumers in Spain, Italy, and Morocco, we estimate the share of nighttime or "off-peak" consumption for both residential and industrial uses (Eurolectric, 2007). These data also provide the tax component of retail electricity prices and allow us to deduce differences in prices between daytime and nighttime residential consumption. ${ }^{21}$ Combining data on country-specific retail electricity tariffs (World Bank, forthcoming) and the proportion of total consumption accruing to industry (IEA, 2007), we estimate average "daytime" and "nighttime" revenue per kWh for southern Europe and each of the selected MENA domestic markets (Table 4). Fuel and production subsidies keep tariffs very low in Libya, Egypt, and Saudi Arabia. Of particular relevance to CSP profitability is the difference between daytime and nighttime prices. While MENA countries exhibit little diurnal variation, it is significant in Europe, where time-of-use tariff structures are common.

\footnotetext{
${ }^{21}$ The tax component is typically $20 \%$ of the retail price in southern Europe and $14 \%$ in Morocco. We assume that the tax share is negligible in other MENA countries.
} 


\begin{tabular}{|c|c|c|}
\hline $\begin{array}{c}\text { Table 4: Estimated } \\
\text { revenue per kWh net of } \\
\text { taxes (cents) }\end{array}$ & $\begin{array}{c}\text { Average } \\
\text { "daytime" } \\
\text { revenue }\end{array}$ & $\begin{array}{c}\text { Average } \\
\text { "nighttime" } \\
\text { revenue }\end{array}$ \\
\hline $\begin{array}{c}\text { Europe (southern) } \\
\text { Morocco }\end{array}$ & 15.3 & 8.1 \\
Libya & 10.4 & 8.5 \\
Egypt & 2.1 & 2.1 \\
Saudi Arabia & 2.1 & 2.2 \\
Jordan & 1.5 & 1.5 \\
\hline
\end{tabular}

We construct revenue streams for various plant configurations, taking into account the prices shown in Table $\mathbf{4}$ and making adjustments for power losses in transmission and distribution. ${ }^{22}$ For example, a CSP plant built in Libya will have a significantly different expected revenue stream for exporting power to Europe than for selling domestically. We assume that a CSP plant without thermal storage sells all of its output at daytime prices, while coal, gas, and CSP storage plants ("base-load” configurations) sell their output roughly consistently over the course of the day. We embed the resulting revenues in the financial model, accounting for corporate income tax rates ranging from an estimated 20\% in Egypt and Saudi Arabia to $35 \%$ in Morocco. We assume that debt is repaid over the full operating life of the plant (30 years).

Table 5 shows illustrative financial model results for domestic coal and natural gas configurations, assuming an interest rate of $7 \%$ and an equity share of $50 \%$. These are the financial (not economic or social) rates of return to the producer and do not include direct government subsidies. The European coal and gas cases are presented for different carbon charges. We adopt $\$ 15$ per ton as representative for emissions credits procured through the

\footnotetext{
${ }^{22}$ Total power system losses (additional to transmission losses reported in Section 3), are estimated for each MENA country and Europe from the IEA's Energy Balances Database (2007).
} 
Clean Development Mechanism (CDM) under the Kyoto Protocol. Our emissions charge of $\$ 30$ per ton is similar to recent and expected charges within the European Union's Emissions Trading System - although this is likely a conservative value over the medium to long term (Capros et al., 2008). We assume that MENA countries face no such charges. In practice, the debt-toequity ratio could be different than assumed here, although for large projects equity shares of 40$60 \%$ are common. ${ }^{23}$

\begin{tabular}{|c|c|c|}
\hline $\begin{array}{c}\text { Table 5: Illustrative Financial } \\
\text { IRR for Coal and Gas Power } \\
\text { Projects (50\% Equity) }\end{array}$ & $\begin{array}{c}\text { Natural Gas } \\
\text { Combined Cycle }\end{array}$ & $\begin{array}{c}\text { Supercritical } \\
\text { Coal }\end{array}$ \\
\hline Europe (no carbon charge) & $23.4 \%$ & $16.9 \%$ \\
Europe (\$15 per ton CO2) & $19.7 \%$ & $13.1 \%$ \\
Europe (\$30 per ton CO2) & $15.6 \%$ & $8.8 \%$ \\
\hline Morocco & $24.1 \%$ & $12.8 \%$ \\
Libya & $0.4 \%$ & $\mathrm{n} / \mathrm{a}$ \\
Egypt & $<0$ & $\mathrm{n} / \mathrm{a}$ \\
Saudi Arabia & $<0$ & $\mathrm{n} / \mathrm{a}$ \\
Jordan & $10.4 \%$ & $\mathrm{n} / \mathrm{a}$ \\
\hline
\end{tabular}

Of primary interest is the profitability of domestic power projects in Europe. Natural gas shows the highest IRR; supercritical coal is considerably lower. With the exception of coal under a $\$ 30$-per-ton $\mathrm{CO} 2$ charge (IRR=8.8\%), all other European coal and gas projects exhibit IRR's close to the range of values historically observed for power generation (Kistner and Price, 1999). The low IRR of European coal projects under a \$30-per-ton CO2 charge suggests that investors supporting coal power generation are either projecting that coal prices will be considerably lower than those assumed here, that electricity prices will increase in the future, or that carbon offsets via the $\mathrm{CDM}$ will be available at a rate similar to the $\$ 15$ per ton $\mathrm{CO} 2$ posited above.

\footnotetext{
${ }^{23}$ http://www.eia.doe.gov/oiaf/aeo/otheranalysis/eegt.html
} 
The financial return to natural gas generation varies across MENA countries, from a robust $24 \%$ in Morocco to actual losses in Saudi Arabia and Egypt. Since the financial model does not include direct subsidies to producers - some of which could be public power generators operating at zero or very low profit - the latter result is not surprising.

For CSP configurations, we fold the cost of transmission into the plant-level financial model. We assume that the plant bears the capital and operating costs of its share of the transmission system capacity. ${ }^{24}$ Although in practice the generation and transmission components would likely be financed separately and owned and operated by different actors, we combine them here for the purposes of comparing the overall profitability of CSP, which requires additional transmission infrastructure, to the fossil fuel alternatives.

None of the CSP options are profitable when the electricity is sold domestically at prevailing tariffs. The European export options for Morocco, Libya, and Jordan all have small but positive expected rates of return, assuming a 75\% equity component (Table 6). The larger assumed equity share for CSP indicates the hurdle posed by high initial capital costs, which limits the amount of leveraging that can be achieved. Given higher initial costs and the lower price of nighttime electricity, systems without thermal storage are consistently more profitable under the assumed financing structure.

\begin{tabular}{|c|c|c|}
\hline $\begin{array}{c}\text { Table 6: Illustrative Financial } \\
\text { IRR for CSP Export Projects } \\
\text { (75\% Equity) }\end{array}$ & $\begin{array}{c}\text { CSP Without } \\
\text { Storage (export } \\
\text { to Europe) }\end{array}$ & $\begin{array}{c}\text { CSP With } \\
\text { Storage (export } \\
\text { to Europe) }\end{array}$ \\
\hline Morocco & $2.6 \%$ & $1.8 \%$ \\
Libya & $2.3 \%$ & $1.9 \%$ \\
Jordan & $3.4 \%$ & $2.6 \%$ \\
\hline
\end{tabular}

\footnotetext{
${ }^{24}$ For example, a $250 \mathrm{MW}$ CSP plant is assumed to bear half of the cost of a $500 \mathrm{MW}$ HVAC transmission system for domestic supply and one-twelfth $(250 / 3,000)$ of the cost of a 3,000 MW HVDC transmissions system for European supply.
} 


\section{Static Analysis of Grants Required for Initial CSP Project Competitiveness}

Numerous public-sector interventions could shift the IRR of CSP projects toward parity with the fossil fuel alternatives. We focus primarily on the use of upfront or recurring grants (subsidies) and simply note that concessionary lending or loan guarantees can be thought of as implicit grants over time. The analytical question is: What grant is required to bring the IRR of CSP generation to equality with fossil fuel alternatives? We assess this question for electricity exports to Europe, and for domestic use of CSP within MENA countries.

\subsection{Export of Electricity to Europe}

For any of the three MENA export options (from Morocco, Libya, or Jordan), we assume that the investor alternative is coal or gas power in Europe. We take the lowest applicable IRR to be $13.1 \%$ (coal power under a $\$ 15$-per-ton $\mathrm{CO} 2$ charge) and calculate the minimum subsidy required to bring CSP up to this level. The upfront subsidy is calculated both with and without the aid of annual CDM financing. Under the CDM scenario, we assume that the CSP project receives an annual payment of $\$ 15$ per ton $\mathrm{CO} 2$ averted, where coal is the fuel source being displaced. ${ }^{25}$ The total subsidy also depends on the debt-to-equity ratio for capital costs not covered by the grant, with greater leveraging (more debt, lower equity) increasing the rate of return to equity as long as the financing structure also ensures an ADSCR of 1.5 or higher. We assume a $7 \%$ interest rate.

Figure 8 shows the relationship between the required subsidy and the project equity component for CSP configurations without thermal storage. Results are shown both with and

\footnotetext{
${ }^{25}$ We recognize that this does not comply with traditional use of the Clean Development Mechanism, where the project's output and counterfactual "baseline" are both limited to the developing country in question, and may not be allowable under existing rules. In our view, which is line with Stern (2008), the scenario we describe should be allowable, enabling a European coal plant to purchase carbon offsets by financing a CSP project in Morocco (for example) that will export electricity to Europe. Since the Moroccan government benefits through additional tax revenue, it can be argued that the "development" component of the CDM remains intact.
} 
without potential CDM revenues. Figure 9 shows the same relationship for CSP with thermal storage.

Figure 8: Grant for 250 MW MENA CSP Export Project Without Thermal Storage

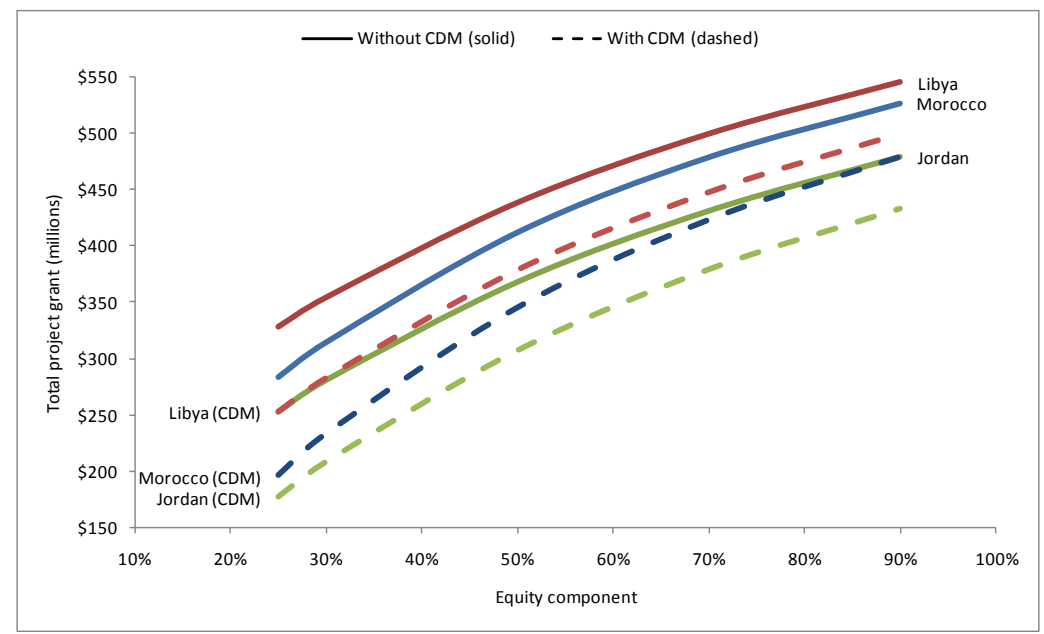

Figure 9: Grant for 250 MW MENA CSP Export Project with Thermal Storage

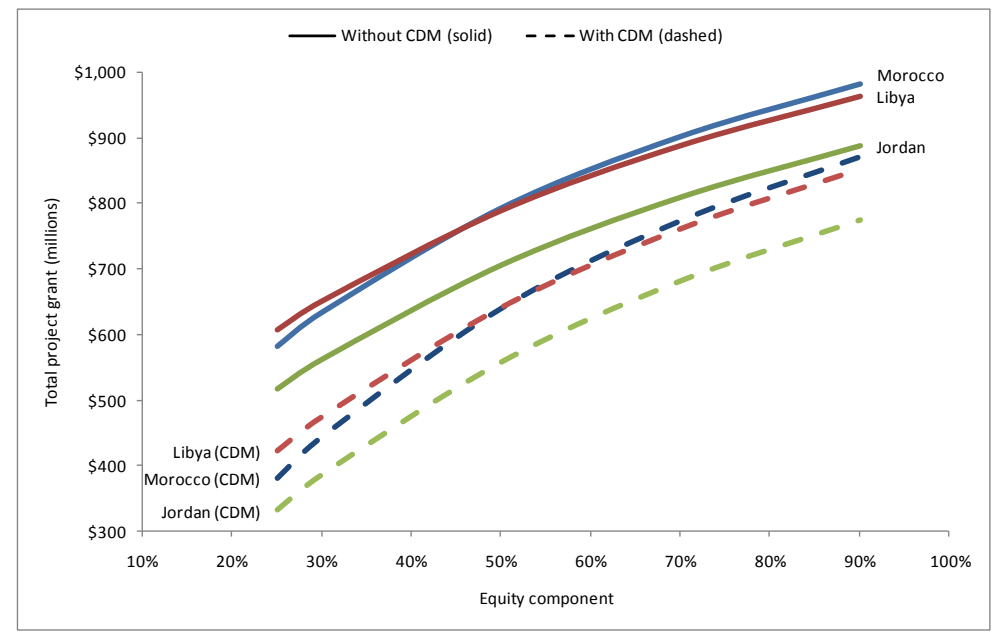

Table 7 reports the estimated subsidy and $\mathrm{CO} 2$ abatement cost for projects whose capital costs not covered by the grant are met through a $50 \%$ equity $/ 50 \%$ debt arrangement, with no CDM financing available. The abatement cost is the total subsidy divided by the present value of $\mathrm{CO} 2$ emissions averted as a result of generating electricity from CSP, as opposed to supercritical coal, adjusting for the additional transmission losses of the former. We report 
values using social discount rates of 5\% and 10\%. Table 8 reports the same information in the case of CDM financing.

\begin{tabular}{|c|c|c|c|c|c|c|}
\hline \multirow{3}{*}{$\begin{array}{c}\text { Table 7: Estimated Subsidy and } \\
\text { CO2 Abatement Costs for Initial } \\
\text { MENA CSP Export Project without } \\
\text { CDM }\end{array}$} & \multicolumn{3}{|c|}{ CSP Without Storage ( 250 MW, $26 \%$ c.f.) } & \multicolumn{3}{|c|}{ CSP With Storage ( 250 MW, $60 \%$ c.f.) } \\
\hline & \multirow{2}{*}{$\begin{array}{l}\text { Total Subsidy } \\
\text { (millions) }\end{array}$} & \multicolumn{2}{|c|}{ Abatement Cost ( $\$$ per ton $\mathrm{CO} 2$ ) } & \multirow{2}{*}{$\begin{array}{l}\text { Total Subsidy } \\
\text { (millions) }\end{array}$} & \multicolumn{2}{|c|}{ Abatement Cost ( $\$$ per ton $\mathrm{CO} 2$ ) } \\
\hline & & $10 \%$ d.r. & $5 \%$ d.r. & & $10 \%$ d.r. & $5 \%$ d.r. \\
\hline Morocco & $\$ 412$ & $\$ 100$ & $\$ 62$ & $\$ 794$ & $\$ 84$ & $\$ 51$ \\
\hline Libya & $\$ 438$ & $\$ 114$ & $\$ 70$ & $\$ 790$ & $\$ 89$ & $\$ 55$ \\
\hline Jordan & $\$ 368$ & $\$ 94$ & $\$ 57$ & $\$ 706$ & $\$ 78$ & $\$ 48$ \\
\hline
\end{tabular}

\begin{tabular}{|c|c|c|c|c|c|c|}
\hline \multirow{3}{*}{$\begin{array}{c}\text { Table 8: Estimated Subsidy and } \\
\text { CO2 Abatement Costs for Initial } \\
\text { MENA CSP Export Project with } \\
\text { CDM }\end{array}$} & \multicolumn{3}{|c|}{ CSP Without Storage ( 250 MW, $26 \%$ c.f.) } & \multicolumn{3}{|c|}{ CSP With Storage ( 250 MW, $60 \%$ c.f.) } \\
\hline & \multirow{2}{*}{$\begin{array}{l}\text { Total Subsidy } \\
\text { (millions) }\end{array}$} & \multicolumn{2}{|c|}{ Abatement Cost ( $\$$ per ton $\mathrm{CO} 2$ ) } & \multirow{2}{*}{$\begin{array}{l}\text { Total Subsidy } \\
\text { (millions) }\end{array}$} & \multicolumn{2}{|c|}{ Abatement Cost ( $\$$ per ton $\mathrm{CO} 2$ ) } \\
\hline & & $10 \%$ d.r. & $5 \%$ d.r. & & $10 \%$ d.r. & $5 \%$ d.r. \\
\hline Morocco & $\$ 345$ & $\$ 84$ & $\$ 52$ & $\$ 640$ & $\$ 68$ & $\$ 41$ \\
\hline Libya & $\$ 379$ & $\$ 99$ & $\$ 60$ & $\$ 642$ & $\$ 72$ & $\$ 44$ \\
\hline Jordan & $\$ 307$ & $\$ 78$ & $\$ 48$ & $\$ 558$ & $\$ 62$ & $\$ 38$ \\
\hline
\end{tabular}

Assuming a 50\% equity arrangement, the estimated cost per ton $\mathrm{CO} 2$ averted for the initial CSP plants is typically $20 \%$ lower for the storage configuration than non-storage, because the plant capacity factor with thermal storage increases faster than the required subsidy. At a $10 \%$ discount rate, the abatement costs range from about $\$ 100$ per ton $\mathrm{CO} 2$ in the case of non-storage CSP without CDM financing, to about $\$ 65$ in the case of thermal storage with CDM. At a 5\% discount rate, the abatement costs range from about $\$ 65$ to as low as $\$ 40$ per ton $\mathrm{CO} 2$. In Section 6, we estimate how abatement costs change over time in response to a concerted effort to drive down the cost of CSP generation.

\subsection{Domestic Supply of Electricity}

We assume that the primary fossil-fuel generation option within MENA countries is natural gas. As in the export case, we calculate the grant required to bring the IRR of CSP to parity with 
the domestic alternative. In cases where natural gas generation is deemed unprofitable (Egypt and Saudi Arabia), we calculate the grant needed for the producer to at least break even.

In addition to the grant, we consider annual CDM financing as well as the potential to redirect obsolete domestic gas subsidies. If a CSP plant is substituted for gas power generation in MENA countries (i.e., CSP successfully provides electricity at the prevailing tariff), the gas subsidies previously used to keep the costs of generation low can be redirected to support CSP projects.

We calculate potential CDM financing under the assumption that the baseline technology is natural gas generation. This results in a potential annual subsidy of about $\$ 3$ million in the case of a $250 \mathrm{MW}$ non-storage CSP plant and about \$7 million with thermal storage. Existing gas subsidies are estimated by assuming that the cost of gas transport to Europe from MENA countries is about $\$ 3$ per MMBtu (ECA, 2007). The assumed European retail price minus the cost of transport gives the border price. The difference between the border price and the subsidized prices gives the implicit subsidy. When applied to natural gas generation, the estimated subsidies range from a low of about $\$ 4$ per MWh in Morocco to nearly $\$ 40$ per MWh in Libya, Egypt, and Saudi Arabia. In the latter case, the potential financial support provided to CSP by redirected gas subsidies is substantial: about $\$ 22$ million per year for non-storage CSP and \$52 million per year for the storage configuration (250 MW).

Figure 10 shows the relationship between the grant requirement and equity component for the case of non-storage CSP generation where CDM financing and redirected gas subsidies are incorporated. Figure 11 does the same for the thermal storage configuration. In Morocco and Jordan, where electricity prices are relatively high and gas subsidies low, the relationship between the grant and equity component is similar to that observed for the European export 
options. Obtaining more credit (lowering the equity component) reduces the required grant while maintaining a given IRR.

In the cases of Libya, Egypt, and Saudi Arabia, however, extremely low electricity prices mean that the ADSCR requirement binds the producer at much lower levels of debt. As the equity component declines, the cost of servicing the additional debt quickly becomes untenable, given the relatively small revenue stream. This necessitates a larger grant in order to reduce the absolute amount of borrowing required to meet the capital costs. Without annual contributions from CDM financing and redirected gas subsidies (especially the latter) to offset low electricity prices, a grant of nearly any size fails to allow CSP projects in these countries to break even.

On the positive side, the analysis of natural gas generation suggests that domestic (mostly public) producers are likely operating at little or zero profit. Assuming that CSP projects can be operated by public entities under the same arrangement, the required grants are potentially quite small, especially if the debt component can be minimized. In the case of CSP with thermal storage, our model suggests that equity components of $75 \%$ or higher would require zero external grant money in Libya, Egypt, and Saudi Arabia. Again, this assumes that the public sector is providing the equity with the expectation of little or zero financial return in order to keep electricity prices low. 
Figure 10: Grant for 250 MW MENA CSP Domestic Project w/o Thermal Storage

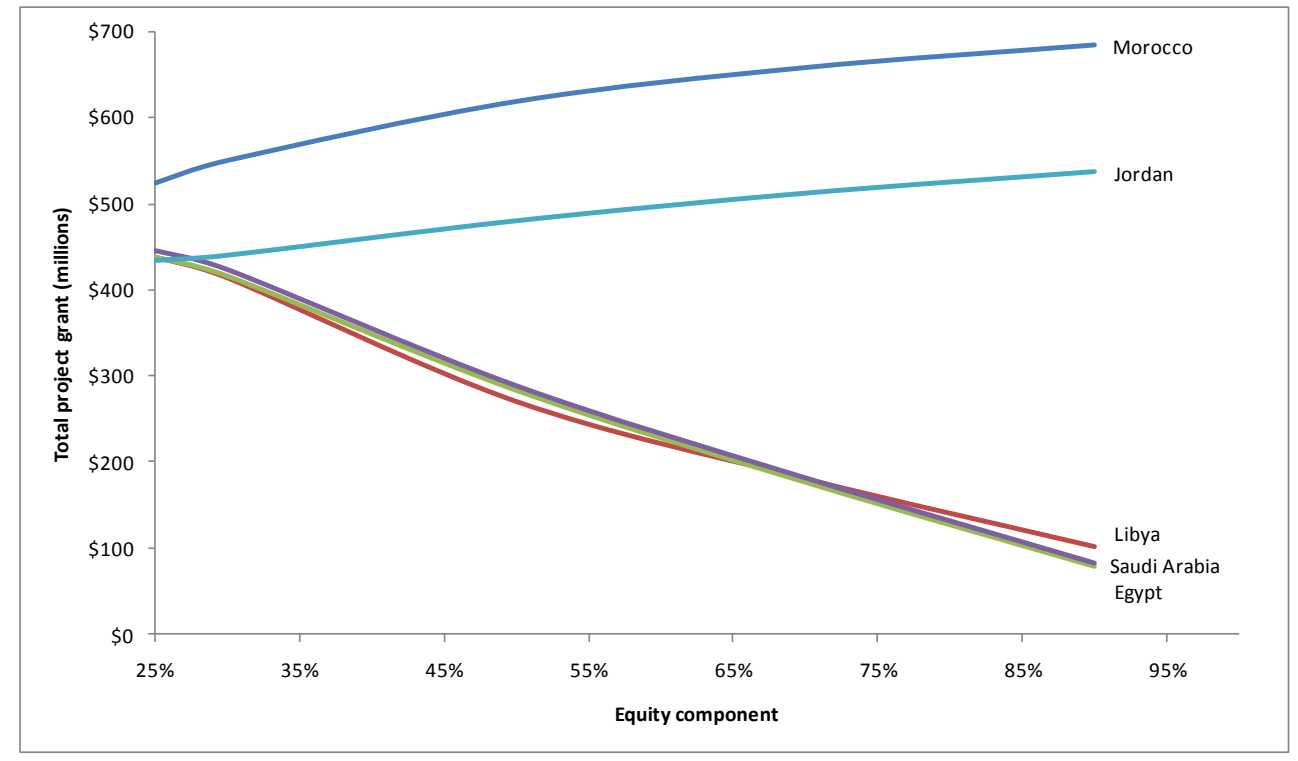

Figure 11: Grant for 250 MW MENA CSP Domestic Project With Thermal Storage

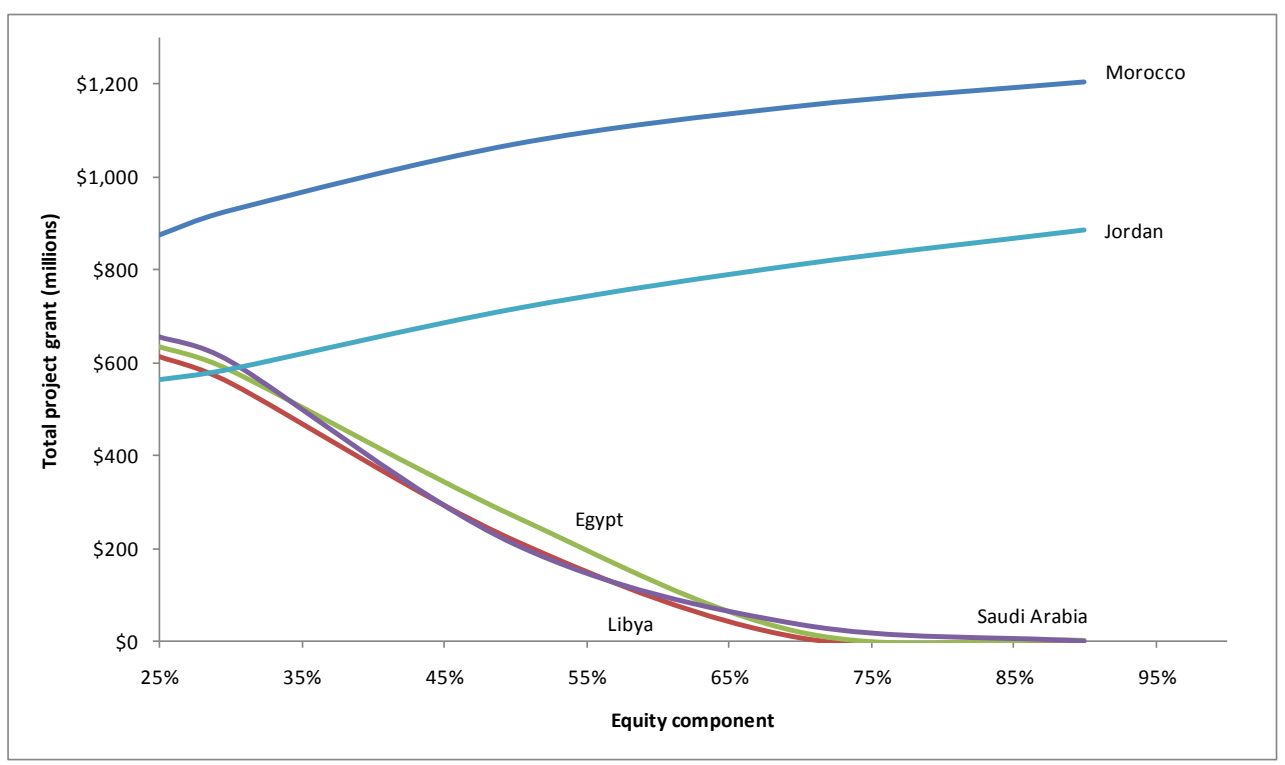

Table 9 shows the estimated subsidies and $\mathrm{CO} 2$ abatement costs for domestic CSP configurations, assuming a 50\% equity arrangement. Since the alternative technology in all cases is relatively clean natural gas generation, the abatement costs are considerably higher than in the case of a coal-power baseline. The benefit of storage systems is more dramatic for 
domestic consumption because of lower diurnal variation in electricity prices than in the European export scenario.

\begin{tabular}{|c|c|c|c|c|c|c|}
\hline \multirow{3}{*}{$\begin{array}{l}\text { Table 9: Estimated Subsidy and } \mathrm{CO} 2 \\
\text { Abatement Costs for Initial Domestic } \\
\text { MENA CSP Project with CDM \& Redirected } \\
\text { Gas Subsidies ( } 50 \% \text { Equity) }\end{array}$} & \multicolumn{3}{|c|}{ CSP Without Storage ( $250 \mathrm{MW}, 26 \%$ c.f.) } & \multicolumn{3}{|c|}{ CSP With Storage ( $250 \mathrm{MW}, 60 \%$ c.f.) } \\
\hline & \multirow{2}{*}{$\begin{array}{l}\text { Total Subsidy } \\
\text { (millions) }\end{array}$} & \multicolumn{2}{|c|}{ Abatement Cost ( $\$$ per ton $\mathrm{CO} 2$ ) } & \multirow{2}{*}{$\begin{array}{l}\text { Total Subsidy } \\
\text { (millions) }\end{array}$} & \multicolumn{2}{|c|}{ Abatement Cost ( $\$$ per ton $\mathrm{CO} 2$ ) } \\
\hline & & $10 \%$ d.r. & $5 \%$ d.r. & & $10 \%$ d.r. & $5 \%$ d.r. \\
\hline Morocco & $\$ 618$ & $\$ 328$ & $\$ 201$ & $\$ 1,070$ & $\$ 246$ & $\$ 151$ \\
\hline Libya & $\$ 270$ & $\$ 143$ & $\$ 88$ & $\$ 215$ & $\$ 49$ & $\$ 30$ \\
\hline Egypt & $\$ 283$ & $\$ 148$ & $\$ 91$ & $\$ 267$ & $\$ 61$ & $\$ 37$ \\
\hline Saudi Arabia & $\$ 288$ & $\$ 151$ & $\$ 92$ & $\$ 208$ & $\$ 47$ & $\$ 29$ \\
\hline Jordan & $\$ 479$ & $\$ 252$ & $\$ 154$ & $\$ 715$ & $\$ 163$ & $\$ 100$ \\
\hline
\end{tabular}

Although we have assumed that MENA governments redirect gas subsidies to CSP projects, this does not mean that the arrangement is budget neutral. Since the natural gas previously used for domestic power generation is replaced by solar energy, it is available for export to Europe. The tax revenues from this transaction result in a net budgetary gain for the government. Assuming full export of the displaced gas, we roughly estimate that construction of a $250 \mathrm{MW}$ non-storage CSP plant might result in additional tax revenues from gas export of about $\$ 5$ million per year (Egypt and Saudi Arabia) to \$9 million per year (Morocco). For the storage configuration, the additional revenue might range from $\$ 12$ to $\$ 21$ million annually.

In the specific case of Morocco, the financial model results change considerably when coal power generation is assumed to be the alternative. This significantly lowers the IRR for CSP relative to the alternative power source (from $24.1 \%$ for gas to $12.8 \%$ for coal) and increases the CDM contribution. Assuming a 50\% equity component, the required grants under these circumstances are estimated to be $\$ 454$ million and $\$ 718$ million for non-storage and storage CSP, respectively. At a 10\%/5\% discount rate, the CO2 abatement cost comes to $\$ 106 / \$ 65$ per ton without storage and $\$ 73 / \$ 45$ per ton with storage. 


\section{Dynamic Analysis of Programmatic Costs over Time}

We now consider the potential for learning and cost reductions over time as CSP is expanded. Although CSP parabolic trough technology has been in commercial operation since the early 1980's, global installed capacity remained largely unchanged from the early 1990's until a few years ago. The recent growth has incorporated a range of new CSP technologies whose potential for learning and cost reductions is high.

In 2007, more than $450 \mathrm{MW}$ of CSP generating capacity was in operation worldwide. Extrapolating near-term estimates of new construction, we conservatively estimate global capacity of at least 4,000 MW by $2012 .^{26}$ The CSP cost estimates in Section 3 are based on projects expected to be in full commercial operation by then.

The speed at which costs fall in response to engineering, construction, and operational experience, improved material procurement, and manufacturing scale is described by the learning rate, which specifies the percentage change in unit costs for each doubling of installed capacity. The literature on technological experience curves and learning rates is extensive. In a review of the evidence for renewable energy technologies, Neij (2008) suggests plausible learning rates of $10 \%$ to $20 \%$ for wind turbines, $20 \%$ for photovoltaic modules, and, based largely on the limited evidence provided by the older California SEGS (parabolic trough) plants, $10 \%$ for CSP. Enermodal's (1999) study of falling capital costs for the SEGS facilities finds a learning rate of $12 \%$. Given the experience of wind and photovoltaic power and the potential for greater cost reductions from large-scale CSP facilities across a range of new technologies, including thermal storage systems, we use illustrative learning rates of $10 \%$ and $20 \%$.

\footnotetext{
${ }^{26}$ This is based on a quadratic extrapolation of figures given in IEA (2008), which specify global CSP capacity of $354 \mathrm{MW}$ in 2006, 468 MW in 2007 and 2,000 MW in 2010.
} 
We simulate a CSP deployment program in the MENA region designed to export electricity to Europe, incorporating the potential effects of learning and cost reduction from both regional and global expansion. The main objective of the program is to displace new coal power facilities in Europe. There are presently more than $9 \mathrm{GW}$ of coal-fired power plants under construction in the region (Platts, 2008). The IEA (2008) projects European coal-generating capacity to remain at about $200 \mathrm{GW}$ for the next two decades under a business-as-usual scenario.

Assuming a maximum operational lifetime of 40 years for coal plants, we estimate that replacing aging European plants could require as much as $8 \mathrm{GW}$ of new coal capacity each year between 2010 and 2020. At least $30 \%$ of that construction (2.5 GW per year) is likely to occur in Spain, Italy, Turkey, and Germany - demand centers near terminal points for our preferred transmission corridors. ${ }^{27}$ Given the lower capacity factors of CSP plants, the total capacity required to offset even a small portion of this coal construction is considerable. ${ }^{28}$

We specify a MENA CSP deployment program that begins construction of plants and transmission infrastructure by 2010 , with commercial operation of the first facilities beginning in 2012. The initial deployment is $500 \mathrm{MW}$ and increases rapidly, reaching 20,000 MW total installed capacity in 2020 . We assume that $25 \%$ of the program's expansion consists of CSP with thermal storage capability. In this scenario, total delivered electricity is about $55 \mathrm{TWh}$ in 2020 - equal to the total electricity production of Austria. The power and transmission facilities constructed during this decade-long program would potentially avert 2.7 billion tons of CO2 over 30 years of operation.

The MENA CSP program is additional to a posited "background" expansion of CSP elsewhere in the world based on extrapolation of recent and planned growth. We compute

\footnotetext{
${ }^{27}$ Figures are based on the authors' analysis of the Platts (2008) world electric power plant database.

${ }^{28}$ Offsetting $2.5 \mathrm{GW}$ of new coal power construction annually would likely require between $3.3 \mathrm{GW}$ (with storage) and 7.7 GW (without storage) of CSP generating capacity.
} 
separate learning effects for the solar array components and storage systems; the power block and transmission technologies are assumed to be mature. Costs of plant operation and maintenance also decline in response to the specified learning rate. Figure 12 shows the resulting levelized costs of electricity for MENA CSP under alternative learning rates given the expansion schedule described above.

\section{Figure 12: Levelized Cost of MENA CSP with Expansion and Learning Effects}

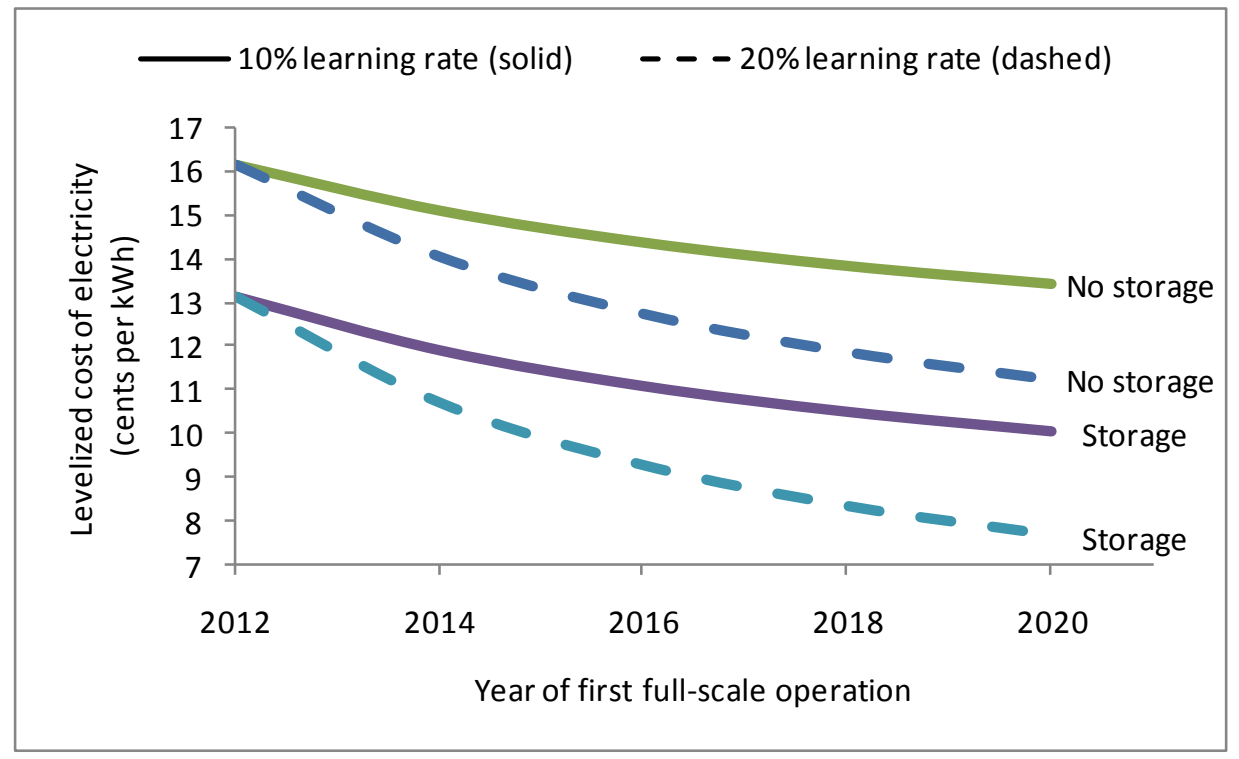

These costs are embedded in the financial model in order to calculate the total subsidies required to meet the stated deployment schedule. As in Section 4, the financial alterative is supercritical coal power in Europe, whose profitability also changes slightly over time in response to projected changes in the price of coal (Figure 7). We calculate required subsidies for each of the three European transmission options, assuming that CSP capacity is allocated evenly among the three sites. We model four scenarios, with and without CDM financing and with learning rates of $10 \%$ and $20 \%$. Figure 13 shows estimated total project subsidies over time. Depending on scenario parameters, the total cost over the course of a decade ranges from $\$ 12$ to $\$ 28$ billion. 
Figure 13: Total Subsidies Required for MENA CSP Deployment of 20 GW by 2020

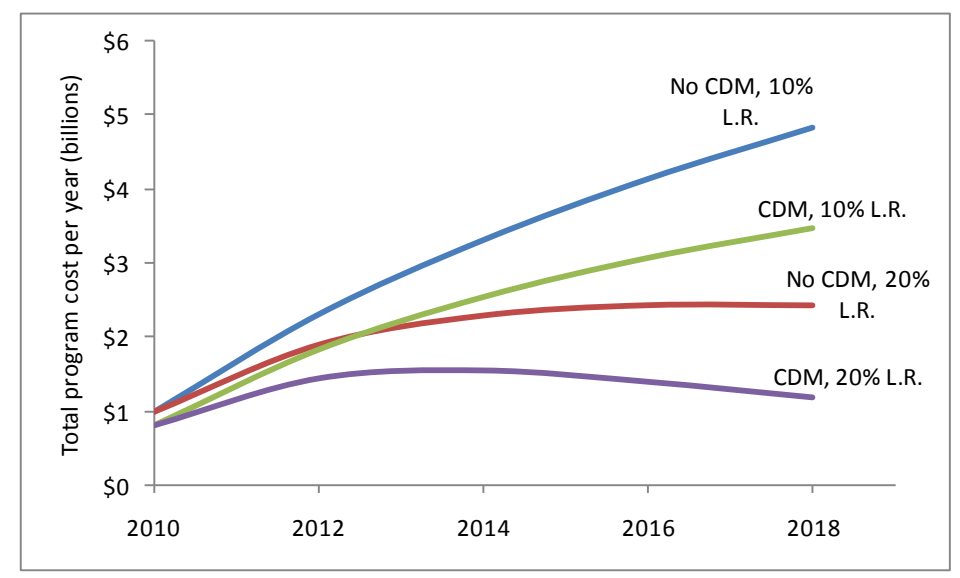

Figure 14 shows the abatement cost of $\mathrm{CO} 2$ as CSP deployment progresses, assuming a 5\% social discount rate. A 10\% discount rate gives values about 60\% higher. In the $20 \%$ learning rate scenarios, abatement costs by the end of the decade are $\$ 10$ per ton $\mathrm{CO} 2$. Even in the most conservative scenario, which employs a $10 \%$ learning rate and no CDM financing, abatement costs by the last year of the program are below $\$ 40$ per ton $\mathrm{CO} 2$.

\section{Figure 14: Program Abatement Cost of $\mathrm{CO} 2$ over Time (5\% discount rate)}

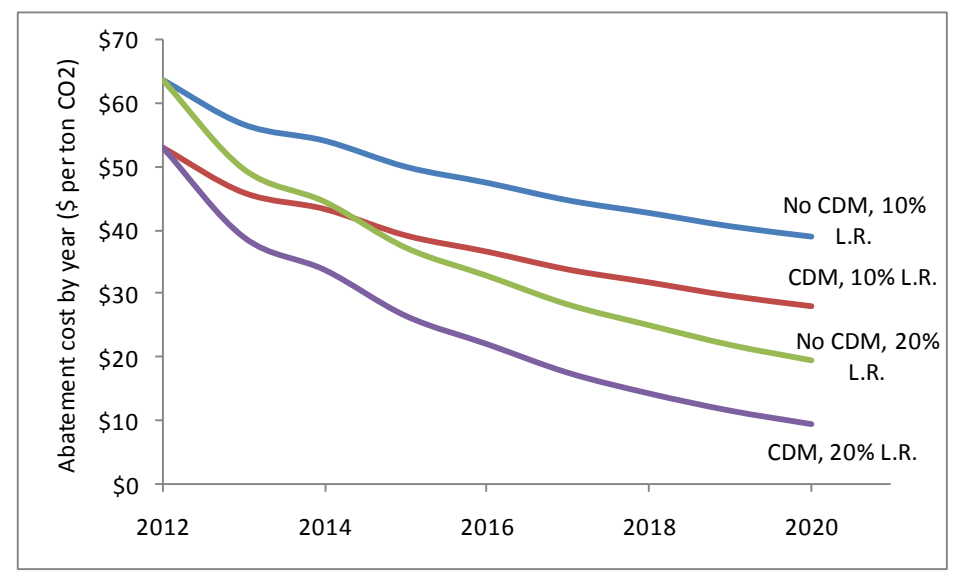

More importantly, the profitability of CSP plants improves steadily over the course of the program as costs decline. Figure 15 shows the expected internal rate of return for European 
coal, European natural gas, and CSP plants over time assuming a moderate $15 \%$ learning rate and CDM financing. These figures do not include subsidies or the additional costs of transmission. Coal and gas plants are assumed to face a $\$ 15$ per ton $\mathrm{CO} 2$ charge, which is likely conservative. By 2020, prospective CSP plants without storage exhibit IRR's competitive with supercritical coal, and storage configurations are as profitable as natural gas plants.

Figure 15: Profitability of Coal, Gas, and CSP Projects over Time (15\% Learning Rate)

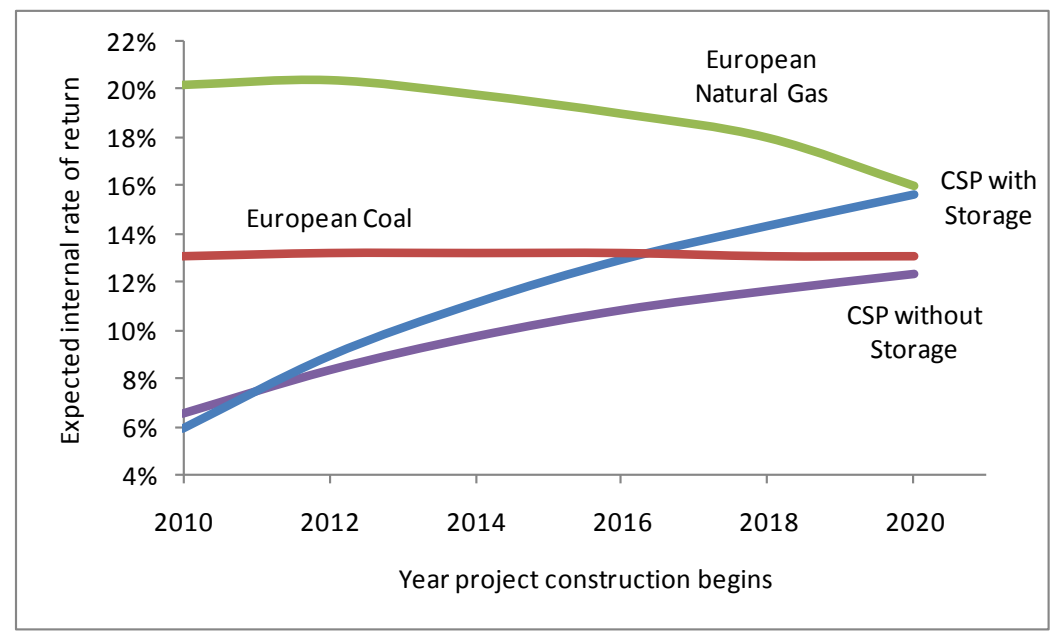

Once parity in expected profitability is achieved, the private sector can drive deployment without the use of public subsidies. This extends the benefits of the subsidized expansion program beyond the period of fund dispersal. Assuming a 15\% learning rate, the background (non-program) rate of global CSP expansion suggests that the MENA program would accelerate cost reductions by about six years.

If we assume that the private sector continues the MENA expansion schedule past 2020, then the first six years of unsubsidized growth are possible only because of the efforts to drive down costs prior to 2020. For the purposes of calculating abatement costs, emissions averted over this period should also be attributed to the program. Discounting all flows of subsidies and averted CO2 back to 2010 gives us the present value of direct and indirect $\mathrm{CO} 2$ abatement over 
the full life of the deployment program. The median value across all scenarios is $\$ 34$ per ton at a social discount rate of $10 \%$ and $\$ 18$ per ton at a rate of $5 \%$. Given that storage CSP is actually more profitable that non-storage CSP by 2020 under a medium-variant scenario, it is not unreasonable to expect the private sector to build primarily CSP with thermal storage facilities post-2020. If this is the case, the full project abatement cost drops even further: $\$ 29$ per ton at a $10 \%$ discount rate and $\$ 14$ per ton at $5 \% .^{29}$

\section{Summary and Conclusions}

In this paper, we have considered the prospects for subsidized promotion of clean technology in a CSP expansion program designed to export electricity to Europe from preferred sites in Morocco, Libya, and Jordan. Construction begins in 2010, with $20 \mathrm{GW}$ of generating capacity and associated transmission infrastructure installed by 2020 . Total power delivery to Europe in 2020 is 55 TWh per year - capable of meeting household electricity demand for 35 million people. The program directly averts about 2.7 billion tons of carbon dioxide (CO2) emissions over the lifetime of the facilities, and indirectly averts an additional 2.6 billion tons by accelerating cost reductions for investments outside the program. We estimate that implementation will require international clean technology subsidies of about $\$ 20$ billion over ten years, with alternative values ranging from $\$ 12$ to $\$ 28$ billion across scenarios. By the end of the program, the expected profitability of unsubsidized CSP projects is competitive with that of coal and gas power generation in Europe. Over the full life of the project, the present value cost of $\mathrm{CO} 2$ averted is as low as $\$ 14$ per ton. This is a very modest carbon shadow price, even by conservative standards.

\footnotetext{
${ }^{29}$ This assumes that $75 \%$ of annual expansion after 2020 consists of storage CSP, the remainder is non-storage.
} 
We also assess the potential for domestic use of CSP within MENA countries. We find good potential for low-cost deployment, but it will depend heavily on country-specific policies with respect to electricity prices and project financing.

Although we focus on grants for expositional simplicity, we do not mean to suggest that grants are the only, or even the preferable means of achieving this transition. In practice, concessionary financing, loan guarantees, equity investments, and/or feed-in tariffs could be used to bring the profitability of CSP to parity with the relevant fossil fuel alternative in a short period of time. Our simplifying assumptions -- CSP plants receive per-kWh revenue consistent with the average price across all fuel sources; prices remain constant in real terms over time - are probably conservative, on balance. In Spain, for example, the government's renewable electricity feed-in tariff is approximately twice what we have assumed for average southern European rates (Desertec, 2008). Access to preferable electricity prices would dramatically reduce the amount of explicit clean technology financing required.

For actual deployment, it seems sensible for the first CSP installations to use the much smaller and technically- and politically-convenient transmission corridor between Morocco and Spain, especially if the Spanish feed-in tariff is extended to imported electricity. Although it is not intimidating from an engineering standpoint, moving large quantities of electricity across multiple borders - as in the case of the Libyan and Jordanian transmission options - might have political implications that would extend project lead times considerably. Since it is costly to step down high-voltage direct current, the proposed lines need to run uninterrupted to the terminal point before distribution can begin.

We have purposely limited the deployment of CSP with storage to $25 \%$ of total program expansion to reflect the fact that storage systems at large scale are not yet in commercial 
operation. There is a clear need for public support of storage configurations in order to reduce uncertainty, costs, and risks. That said, the relative underdevelopment of CSP thermal storage systems does not limit the potential for profitable and effective deployment of CSP without storage. This is especially true when diurnal variation in electricity prices is significant, either as a result of time-of-use pricing structures or feed-in tariffs specific to daytime solar power.

For the MENA region, a particularly appealing possibility not assessed here is hybrid CSPgas technology for either domestic use or export. CSP plants using sunlight during the day and piped natural gas at night to run the same power block could achieve 24-hour generation at potentially low average cost and emissions. This would have the added benefit of reducing the levelized cost of both generation and associated transmission infrastructure by achieving higher electricity throughput. Supplemental gas could provide an ideal fuel "bridge" as thermal storage systems are refined and developed at scale.

For domestic use of CSP, feasibility will depend largely on MENA governments' approach to electricity pricing and gas subsidies. At electricity prices as low as those in Libya, Saudi Arabia, and Egypt, it is difficult to make CSP operations profitable at current costs. However, redirecting displaced gas subsidies could provide considerable assistance. Preferential tariff treatment for CSP facilities would provide perhaps the simplest way to increase competitiveness. The possibility of strong public-sector investment in CSP with the intention of providing power at little or no financial profitability could allow for rapid deployment at small cost to international donors. Since the potential economic benefits from the export of electricity or displaced natural gas to Europe are immense, MENA governments have a stake in seeing CSP deployed quickly in the region. Indeed, the upside is so large that MENA country self-financing 
of large-scale pilot projects could make sense, thereby reducing risk and the cost of capital for future investments.

Overall, large-scale deployment of CSP in the MENA region is clearly attainable at levels of public subsidy that are modest, given the planetary stakes. The question is not whether CSP is feasible, but whether programs like the MENA initiative will be operational in time to prevent catastrophic climate change. For such programs to spur the clean energy revolution, efforts to arrange financing should begin right away, with site acquisition and construction to follow within a year. 


\section{References}

Capros, P., Mantzos, L., Papandreou, V., Tasios, N. (2008), "Model-based Analysis of the 2008 EU Policy Package on Climate Change and Renewables," E3MLab/NTUA.

Cova, B., Pincella, C., Simioli, G., Stigliano, G. Paolo, Vailati, R., Zecca, B. (2005), "HVDC Interconnections in the Mediterranean Basin," Inaugural IEEE PES 2005 Conference and Exposition in Africa.

Desertec (2008), “DESERTEC Concept Note,” Trans-Mediterranean Renewable Energy Cooperation, The Club of Rome. Available online:

http://www.desertec.org/downloads/summary_en.pdf

DLR (2005). "Concentrating Solar Power for the Mediterranean Region," German Aerospace Center. Available online: www.dlr.de/tt/med-csp

DLR (2006), “Trans-Mediterranean Interconnection for Concentrating Solar Power," German Aerospace Center. Available online: $\underline{w w w . d l r . d e / t t / t r a n s-c s p}$

ECA (2007), “Egypt: Economic Costs of Natural Gas,” Economic Consulting Associates and Parsons Brinckerhoff, prepared for The World Bank.

Enermodal (1999), "Cost reduction study for solar thermal power plants," Enermodal Engineering Limited, prepared for The World Bank.

ESMAP (2007), "Technical and Economic Assessment of Off-grid, Mini-grid and Grid Electrification Technologies," Energy Sector Management Assistance Program, Technical Paper 121/07. Available online: http://www.esmap.org/filez/pubs/4172008104859_Mini_Grid_Electrification.pdf

ESMAP (2008), "Study of Equipment Prices in the Power Sector (Draft), Energy Sector Management Assistance Program. Available online: http://www.esmap.org/filez/pubs/724200833229_power_prices.pdf

Eurolectric (2007), "Electricity Tariffs as of 1 January 2007," Tariffs Network of Experts, Union of the Electricity Industry.

ICP (2008), “Global Purchasing Power Parities and Real Expenditures,” International Comparison Program, World Bank. Available online:

http://siteresources.worldbank.org/ICPINT/Resources/icp-final.pdf

IEA (2007), "Beyond 2020: Energy Balances of OECD Countries”, International Energy Agency, Paris.

IEA (2008), “World Energy Outlook 2008,” International Energy Agency, Paris. 
IPCC (2007), “Working Group III Report: Mitigation of Climate Change.” Intergovernmental Panel on Climate Change. Chapter 1. Available online: http://www.ipcc.ch/pdf/assessmentreport/ar4/wg3/ar4-wg3-chapter1.pdf.

Kistner, R. and Price, H.W. (1999), "Financing Solar Thermal Power Plants,” National Renewable Energy Laboratory, Proceedings of the ASME Renewable and Advanced Energy Systems for the 21st Century Conference.

May, N. (2005), "Eco-balance of Solar Electricity Transmission from North Africa to Europe," Technical University of Braunschweig Diploma Thesis.

McCormick, D. (2008), "Remarks by Treasury Under Secretary David H. McCormick on China's Journey to Environmentally Sustainable Growth at the West Coast Leadership Dialogue.” Press Release. January 14. Available online: www.ustreas.gov/press/releases/hp761.htm.

Mills, D. and Morgan, R. (2008), "Solar Thermal Electricity as the Primary Replacement for Coal and Oil in U.S. Generation and Transportation," Ausra, Inc. Available online: http://www.ausra.com/pdfs/ausra_usgridsupply.pdf

MIT (2007), "The Future of Coal," Massachusetts Institute of Technology. Available online: http://web.mit.edu/coal/

Neij, L. (2008), "Cost development of future technologies for power generation - A study based on experience curves and complementary bottom-up assessments," Energy Policy, Volume 36, Issue 6.

NETL (2007), "Fossil Energy Cost and Performance Baseline Studies,” National Energy Technology Laboratory. Available online: http://www.netl.doe.gov/energyanalyses/baseline_studies.html

Platts (2008), “World Electric Power Plants (WEPP) Database,” June 2008 version.

Razavi, H. (2008), "Natural Gas Pricing in Countries of the Middle East and North Africa," World Bank draft paper.

Stern, N. (2008), "Economics of Climate Change.” American Economic Review 98 (2): 1-37.

Verdin, K.L., Godt, J.W., Funk, C., Pedreros, D., Worstell, B., Verdin, J. (2007), "Development of a Global Slope Dataset for Estimation of Landslide Occurrence Resulting from Earthquakes," U.S. Geologic Survey, Colorado, Open-File Report 2007-1188.

Wheeler, D. and Ummel, K. (2007), “Another Inconvenient Truth: A Carbon-Intensive South Faces Environmental Disaster, No Matter What the North Does," Center for Global Development Working Paper No. 134. Available online: http://www.cgdev.org/content/publications/detail/14947. 
World Bank (forthcoming), Untitled draft paper of MENA region energy efficiency and subsidies. 